"In Preparation for Applied Thermal Engineering Journal"

\title{
Quantifying the impact of urban wind sheltering on the building energy consumption
}

\author{
Saber Khoshdel Nikkho ${ }^{1}$, Mohammad Heidarinejad ${ }^{1}$, Jiying Liu ${ }^{2}$, and Jelena Srebric ${ }^{1}$ \\ ${ }^{1}$ Department of Mechanical Engineering, University of Maryland, College Park, MD 20742, USA \\ ${ }^{2}$ School of Thermal Engineering, Shandong Jianzhu University, Jinan, China 250101
}

\begin{abstract}
Current building energy simulation approaches usually do not take into account the influence of the surrounding urban neighborhood on the energy consumption patterns. This study aims to address this limitation and quantify the impact of an urban neighborhood. Therefore, the current study develops and validates a framework using Computational Fluid Dynamics (CFD) and building energy simulations. The developed framework in this study relies on deriving wind multipliers for eight principal directions to adjust the wind velocity encountering the building of interest. The purpose of these wind multipliers is to adjust wind velocities in the weather data input files for building energy models. To support the developed framework, this study validated the simulated CFD temperatures with on-site measured data as well as compared the simulated heating and electricity consumptions with the metered energy consumptions. A comparison between the building energy simulation results using both the adjusted and original weather data indicates that the total building energy consumption decreased by 5\%. Among the heat gain components, the infiltration component had the maximum percentage of reduction with $31 \%$ and $29 \%$ sensible cooling and heating decrease, respectively. Overall, even though the annual cooling energy demand increased, the energy demand decreased due to the decrease in the heating demand for the studied neighborhood located in the Northeastern USA.
\end{abstract}

\section{Keywords}

Building energy simulations, Computational Fluid Dynamics, Local wind flow, Neighborhood effects, Urban Microclimate

\section{Introduction}

Buildings located in an urban neighborhood are one of primary contributors to the variation of thermal, airflow, and air pollution patterns in the built environment [1]. Understanding of the urban microclimate is crucial in the design

\footnotetext{
${ }^{1}$ Corresponding Author:

Email: jsrebric@umd.edu (J. Srebric)

Phone: +1 3014051624

Fax: +1 3013149477
} 
of sustainable urban neighborhoods or restoration of existing urban neighborhoods [2]. However, modeling of urban neighborhoods requires to numerically solve a universal system of equations including airflow, temperature, and concentration of contaminants that are time consuming and for certain scales even intractable [1]. A suggestion to solve this system of equations is to limit the energy and airflow modeling at the neighborhood scale for the simulation of built environments [1]. Existing studies conducted numerical simulations of outdoor airflows using CFD coupled with energy simulation of buildings located in urban neighborhoods [3-6]. However, due to the complexity in modeling interaction of buildings in neighborhoods, current studies have strict requirements for the full coupling or interactive co-simulation. These requirements include the data exchange of only the most significant parameters between different models, such as temperature values from energy models to CFD models. This study aims to develop a framework to consider another significant parameter that is the local wind sheltering to provide an effective approach for co-simulation of CFD and building energy models.

A successful modeling of heat transfer processes for buildings located in an urban neighborhood requires consideration of solar radiation [7-9], conduction through walls [10], outdoor convection [11-13], and evapotranspiration of pervious surfaces $[14,15]$. Various models exist in building energy models to account for the solar radiation and conduction through walls/windows. Depending on the urban morphology, building insulation, building internal loads, and location of the building, exterior Convective Heat Transfer Coefficients (CHTC) could be one of the key physical factors affecting the energy consumption patterns for the buildings located in urban neighborhoods [16-18]. Calculation of the CHTCs requires consideration of the local wind; consequently, for the buildings located in urban neighborhoods, CFD is an appropriate tool to calculate the CHTCs [17-20]. One important factor in the heat transfer processes is the influence of the wind velocity and direction on the formation of thermal and velocity boundary layers. Moreover, the urban morphology and relative location of the buildings in urban neighborhoods affects the wind speed and directions, leading to sheltering or channeling of the wind in the neighborhood [21]. Therefore, the current study considers influence of the wind speed and direction among the other influential factors.

An important implication of the wind velocity and direction is on the air infiltration into the buildings. Infiltration rates include both the forced convection due to the influence of wind velocities and the natural convection due to the temperature differences between inside and outside air. Selection of appropriate infiltration rates could significantly affect the building energy consumption patterns [22]. A study showed that the energy loss due to infiltration varied between $6 \%$ and $9 \%$ of the total energy in the U.S. [23]. Another recent study confirmed that infiltration is responsible for $13 \%$ and $3 \%$ of the heating and cooling loads, respectively for the U.S. office buildings [24]. Thus, in this study, the developed framework modifies the wind velocities in the weather data files to account for the impacts of local wind velocities on the implementation of infiltration models in the building energy models.

This study benefits from four open source simulation tools, including OpenFOAM, OpenStudio, EnergyPlus, and Radiance to perform the simulations and validate the simulation results with on-site measured temperatures, and building metered energy data. The current study uses OpenFOAM for the CFD simulations because other existing studies demonstrated the capability of OpenFOAM to provide reliable results for non-isothermal urban environments [25, 26], and isothermal urban airflows [27]. Radiance, a ray tracing tool, provides the thermal boundary conditions driven by radiative fluxes for the CFD simulations [9]. For the building energy modeling, this study uses Virtual PULSE to create the baseline models and modifies these models using OpenStudio and EnergyPlus [28]. Overall, this study relies on the open-source tools, experimental measurements, and metered energy consumption interval data to develop a novel analysis framework. The development of the proposed framework entails following four steps:

(1) Validate CFD simulated temperatures with measured on-site temperatures, and verify quality of the CFD simulations by comparing y-plus values with the ones found in the literature.

(2) Generate wind multipliers for the average measured wind velocities considering an incoming wind speed of $1 \mathrm{~m} / \mathrm{s}$ as the baseline value for CFD simulations. 
(3) Adjust the wind velocities in the energy models using the input weather data file processed with the calculated wind multipliers for the eight principal directions.

(4) Compare the energy consumption patterns for a specific building case study using both processed and original weather data files.

\section{Research Methodology}

Figure 1 presents the workflow deployed to develop the proposed framework for quantifying the impact of urban wind sheltering on the energy consumption patterns of buildings located in an urban neighborhood. The development of the framework entails four different steps of: (1) Creating CFD airflow and building energy models, (2) Validating the simulated airflow temperatures with the actual on-site measured temperatures in an urban neighborhood, (3) Developing wind multipliers using CFD simulations to adjust the wind velocities in the weather data file, and (4) Calibrating the building energy models with the new weather file.

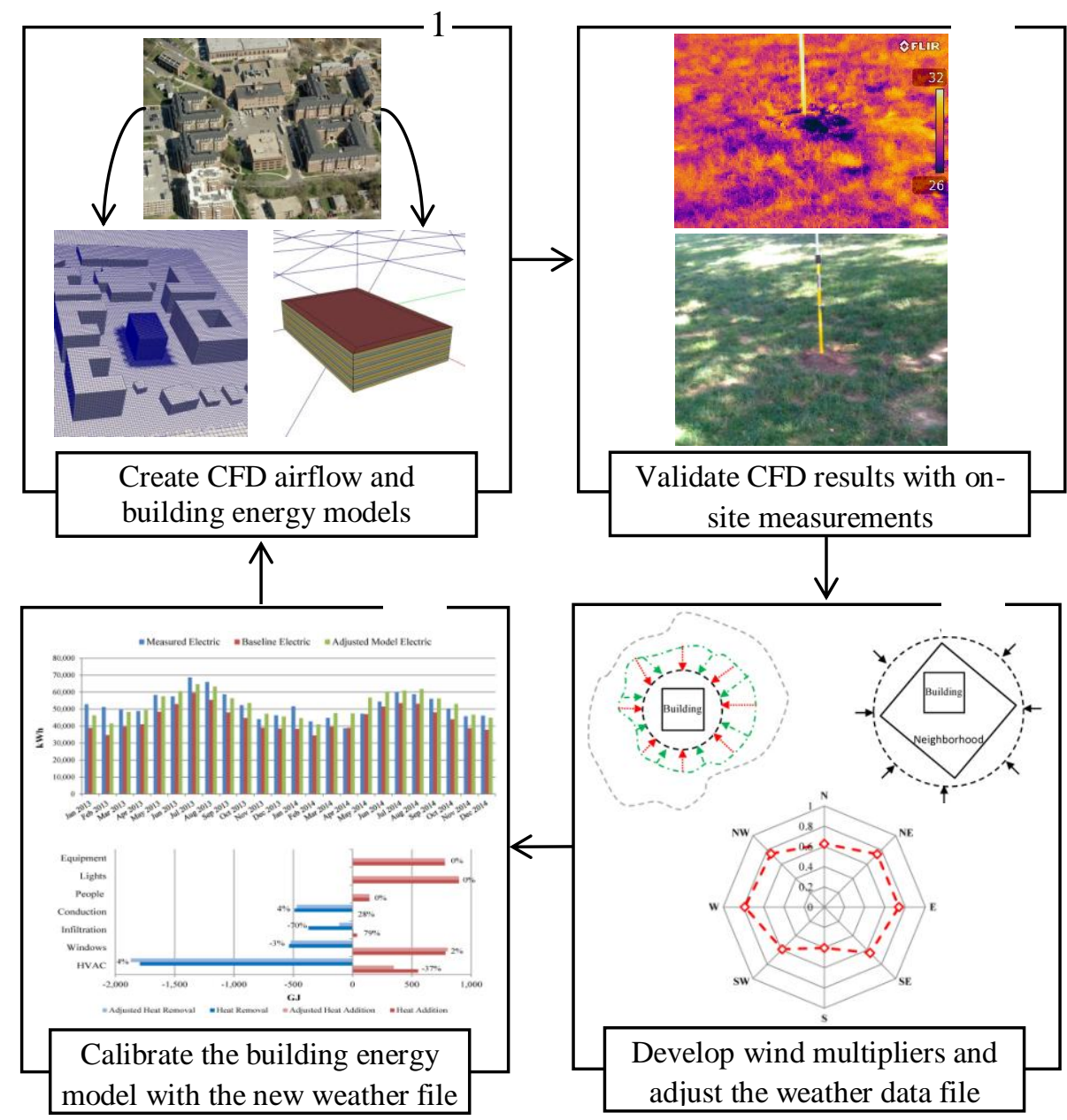

Figure 1: The developed framework to consider the influence of wind sheltering on building energy models

\subsection{Governing Equations}

The governing equations for this simulation encompass mass, momentum and energy conservation equations. Using the RANS (Reynolds Averaged Navier-Stokes) modeling, the time averaged equations with the consideration of mean and fluctuating terms for incompressible flow with the Boussinesq approximation lead to Equations (1) to (3):

$\frac{\partial u_{i}}{\partial x_{i}}=0$ 
$\frac{\partial}{\partial x_{j}}\left(u_{i} u_{j}\right)=-\frac{1}{\rho} \frac{\partial p_{r g h}}{\partial x_{i}}+\frac{\partial}{\partial x_{j}}\left[v\left(\frac{\partial u_{i}}{\partial x_{j}}+\frac{\partial u_{j}}{\partial x_{i}}\right)-\overline{u_{\imath}^{\prime} u_{j}^{\prime}}\right]-\rho_{o} g_{i} \beta\left(T-T_{r e f}\right)$

$u_{j} \frac{\partial T}{\partial x_{j}}=\frac{\partial}{\partial x_{j}}\left(\alpha \frac{\partial T}{\partial x_{j}}-\rho c \overline{v^{\prime} T^{\prime}}\right)$

In the conservation equations, $u, v,-\rho u_{i}^{\prime} u_{j}^{\prime}, \beta, T, p_{\rho g h}$ are the velocity, the kinetic viscosity, the Reynolds Stress, thermal expansion, the air temperature, $p-\rho g z$, respectively. To approximate the Reynolds stress tensor, this study relies on the eddy viscosity model:

$u_{i}^{\prime} u_{j}^{\prime}=v_{t} \frac{\partial u}{\partial x_{i}}$

Where $v_{t}$ is the eddy viscosity, and it is equal to $v_{t}=C_{u} \frac{k^{2}}{\epsilon}$. In this correlation, $k, \epsilon$, and $C_{u}$ are the turbulent kinetic energy, the turbulent dissipation, and a constant equals to 0.0845 , respectively. For the temperature equation, turbulent thermal diffusivity is assumed as $\alpha_{t}=v_{t} / P r_{t}$. In this equation, $P r_{t}$ is the turbulent Prandtl number, and it is equal to 0.8 .

On the building external walls, EnergyPlus calculates the energy conservation at the interior and exterior building surfaces using the heat balance heat equation:

$q^{\prime \prime}{ }_{\alpha s o l}+q^{\prime \prime}{ }_{L W R}+q^{\prime \prime}{ }_{\text {conv }}-q^{\prime \prime}{ }_{k o}=0$

Where $q^{\prime \prime}{ }_{\alpha s o l}, q^{\prime \prime}{ }_{L W R}, q^{\prime \prime}{ }_{\text {conv }}, q^{\prime \prime}{ }_{k o}$ are the absorbed solar radiation, the net longwave radiation, the convective heat transfer, and the conductive heat transferred through the building envelope, respectively.

Three common methods in EnergyPlus to calculate the infiltration rates are: (1) Design Flow Rate, (2) Effective Leakage Area, and (3) Flow Coefficient [29]. Among these methods, this study uses the Design Flow Rate method due to the applicability of this method for integration with CFD simulations through the coefficients allowing the implementation of CFD results in the building energy simulations. Design Flow Rate method assumes:

Infiltration $=\left(I_{\text {design }}\right)\left(F_{\text {schedule }}\right)\left[A+B \mid\left(T_{\text {zone }}-T_{\text {adb }} \mid+C(\right.\right.$ WindSpeed $)+D\left(\right.$ WindSpeed $\left.\left.^{2}\right)\right]$

Where $F_{\text {Schedule }}, T_{\text {zone }}$, and $T_{a d b}$ are the values for user-defined schedule, the zone air temperature, and the outside dry-bulb temperature, respectively. Selection of the coefficients, A, B, C, and D require careful consideration and additional effort. EnergyPlus uses 1, 0, 0, and 0 as default values for A, B, C, and D, respectively. These assumptions only provide a constant volume flow of infiltration under all conditions, further suggesting the need to use modified coefficients for accurate simulations [30]. Therefore, this study benefits from the results of existing studies to implement urban neighborhood based coefficients for the calculation of infiltration rate.

\subsection{CFD Model}

Heat transfer rates and associated computational times in building energy models and airflow models are different in the built environment. For example, the time required for a wall to reach to a steady state condition is significantly different than the time required for the air temperature. These differences suggest that there is a need to consider 
different scales for the building and airflow simulations. Consequently, the transient term in the momentum equation is less significant compared to the convection and diffusion terms. This makes possible to conduct steady state airflow simulation through snapshots in time. This study conducts steady state CFD simulations to couple the airflow and energy models. The use of steady state analysis allows modeling outdoor airflow at different important points in time. The wind rose of the modeled neighborhood provides the predominant wind speeds and directions for the modeling. One important aspect of modeling with CFD is the validation process. This study first validates the OpenFOAM CFD simulations for an actual neighborhood at the University of Maryland.

One of the benefits in using OpenFOAM is the scripted functionality in order to automate the meshing process, using snappyHexMesh utility and developed C++ codes. Even with the complexity of conducting the CFD simulations in urban neighborhoods, a deployment of snappyHexMesh allows to effectively control input parameters and provides a reliable mesh quality for automatic meshing of the simulation domain. OpenFOAM requires the building and the ground geometries in STeroLithograpgy (STL) format and further meshes the domain. The background mesh uses the OpenFOAM built-in tool named blockMesh, and the domain mesh uses the snappyHexMesh utility. Specifically, SnappyHexMesh automatically generates three-dimensional meshes utilizing hexahedral and split-hexahedral from triangulated surface geometries in STL format. The mesh approximately conforms to the surface by iteratively refining a background mesh in the first step, snapping to surfaces in the second step, and adding mesh surface layers at the last step [25].

Based on the literature recommendations [27, 31, 32], an important aspect of each CFD simulation is the Verification and Validation $(\mathrm{V} \& \mathrm{~V})$. The verification requires demonstration of the model represents the mathematical model. Grid Convergence Index (GCI) is a measure to verify the model convergence rate. Therefore, this study uses the following equation to assess the GCI of the simulation results:

$G C I=\frac{F_{S}|\epsilon|}{\left(r^{p}-1\right)}$

Where $F_{s}, \epsilon$, and $p$ are the safety factor, error between the current and refined mesh, and order of convergence, respectively. In this study, $F_{S}$ is 1.25 , and the calculated convergence rate is 1.7 . Overall, this study uses 15 million cells for the refined mesh to reach to an average GCI of $4 \%$. To make sure the results of the study is validated, there is a need to validate the simulation results with the experimental measurements. There are different aspects to consider the variable for the validation. There are two main variables for the validation in modeling outdoor airflow simulations: (1) air velocity and (2) air temperature. Current studies demonstrated that the impact of the ground boundary conditions on the simulated air and temperature results [9]. While a ground temperature difference of $3^{\circ} \mathrm{C}$ could cause up to $20 \%$ discrepancy between the simulated temperature reading close to the ground, the same boundary condition shows up to $0.05 \%$ discrepancy in the simulated air temperature close to the ground. Due to this observation, cost of the anemometers compared to the temperature sensors, and limitations of installing anemometers in outdoor open spaces, this study benefited from an indirect validation of the CFD simulation results with validation of the outdoor air temperatures [20,25].

\subsection{Energy Models}

An accurate building energy model may require extensive calibration, including data collected via on-site measurements. In the simulations, calibration is a process of adjusting or tuning the free parameters in a model, so the model complies with the experimental data [31, 32]. In the building energy modeling, as ASHRAE Guideline 14 2002 provides the requirements for a calibrated model [33]. This study benefits from the reduced-order building energy modeling methods to create the baseline building energy model using Virtual PULSE [28]. The benefits of using reduced-order building energy models as the baseline is to represent building energy consumption performance close to the actual building energy consumption patterns while the model requires minimal detailed on- 
site collection [34]. Figure 2 illustrates the building enclosure defined in the energy model and the actual building of interest.

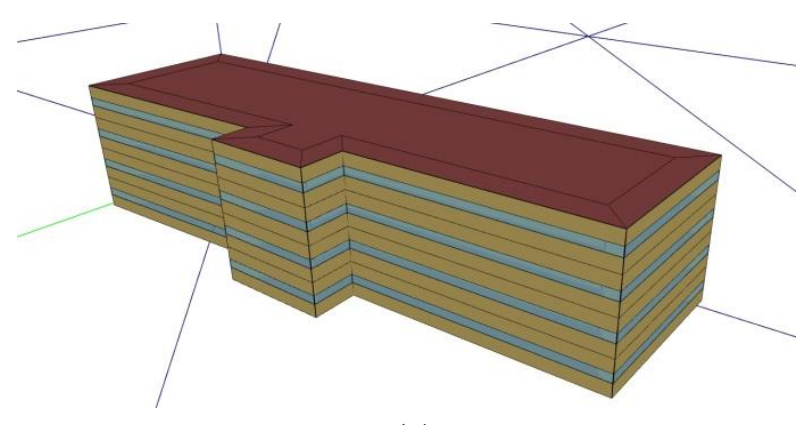

(a)

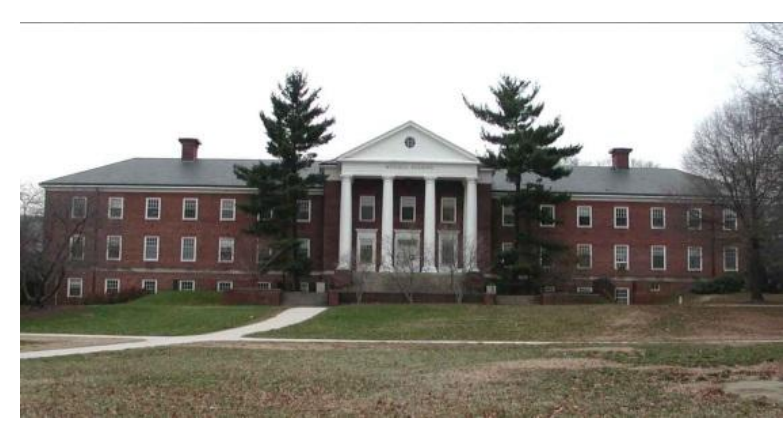

(b)

Figure 2: (a) The building OpenStudio model and (b) the actual building of interest

The calibration of the baseline building energy model for this campus building defines the main input parameters identified in the literature [28, 34-36]. Based on these references, there are common adjustments made during energy model calibration with monthly utility data. Table 1 provides a summary of the inputs in the building energy model. For the model calibration, the primary modified parameters are infiltration, setpoint temperatures and associated schedules, as well as internal loads and associated schedules, to meet the actual building operation.

Table 1: The summary of the inputs in the building energy model

\begin{tabular}{|c|c|}
\hline Building parameters & Summary of Inputs \\
\hline Geometry and Shape & $\begin{array}{l}\text { Shape: } \mathrm{T} \text { shape } \\
\text { Stories: } 4 \text { floors } \\
\text { Floor to floor height: } 3 \mathrm{~m}\end{array}$ \\
\hline Information & $\begin{array}{l}\text { Year built: } 1958 \\
\text { Type: office } \\
\text { Weather: AMY (Actual Methodological Year) College Park, MD } 2014\end{array}$ \\
\hline Construction & Construction sets: DOE Pre-1980 Reference Buildings \\
\hline Spaces & $\begin{array}{l}\text { Window to wall ratio: } 33 \% \\
\text { Thermal zoning: Perimeter and core zoning with single space type } \\
\text { Perimeter zone depth: } 3 \mathrm{~m}\end{array}$ \\
\hline Loads & $\begin{array}{l}\text { Lighting: } 20 \mathrm{~W} / \mathrm{m}^{2} \\
\text { Electric equipment: } 10 \mathrm{~W} / \mathrm{m}^{2} \\
\text { Infiltration: } 0.002 \mathrm{~m}^{3} / \mathrm{m}^{2} . \mathrm{s} \text { of exterior surface area }\end{array}$ \\
\hline $\begin{array}{l}\text { HVAC } \\
\text { (Heating, Ventilating and } \\
\text { Air Conditioning) }\end{array}$ & $\begin{array}{l}\text { System: Rooftop Variable air Volume (VAV) with reheat } \\
\text { Cooling: Direct Expansion (DX) } \\
\text { Heating: District Heating } \\
\text { Fan efficiency: } 70 \% \\
\text { Ventilation: } 0.3048 \mathrm{lit} / \mathrm{s} \cdot \mathrm{m}^{2}\left(0.06 \mathrm{cfm} / \mathrm{ft}^{2}\right)+0.002360 \mathrm{~m}^{3} / \text { person }(5 \mathrm{cfm} / \text { person })\end{array}$ \\
\hline Schedules & Operation schedules: $7 \mathrm{AM}$ to $4 \mathrm{PM}$ based on the electricity use patterns \\
\hline Setpoints & Setpoints: Modified temperature setbacks \\
\hline
\end{tabular}

The baseline building energy model for this study uses the Design Flow Rate model specified in Equation (6), using fixed infiltration rate values. However, there is a need to benefit from accurate infiltration model coefficients to account for the influence of urban neighborhoods reflecting actual wind conditions at building enclosure [37]. The 
calibrated energy model utilizes the modified infiltration model coefficients from a recent study [30]. Table 2 provides these coefficients when the model, represented by Equation (6), for the baseline and calibrated models.

Table 2: Modifications in design flow rate model in the building energy model

\begin{tabular}{|l|l|l|l|}
\hline Coefficient & Description & Baseline & Calibrated \\
\hline A & Constant term & 1 & 0 \\
\hline B & Temperature term & 0 & 0.0138 \\
\hline C & Wind velocity term & 0 & 0 \\
\hline D & Wind velocity squared term & 0 & 0.0315 \\
\hline
\end{tabular}

This study derives the operation schedule for the internal loads from the 15 minutes electricity consumption patterns. Figure 3 illustrates the use patterns for the entire 2014. As the figure shows the operation schedules follows the Building Management System (BMS). The calibrated building energy model benefits from the derived schedules. In addition, the calibrated building energy model relies using the university guidelines for the building operation, conducting building walkthroughs, and accessing to the control systems.

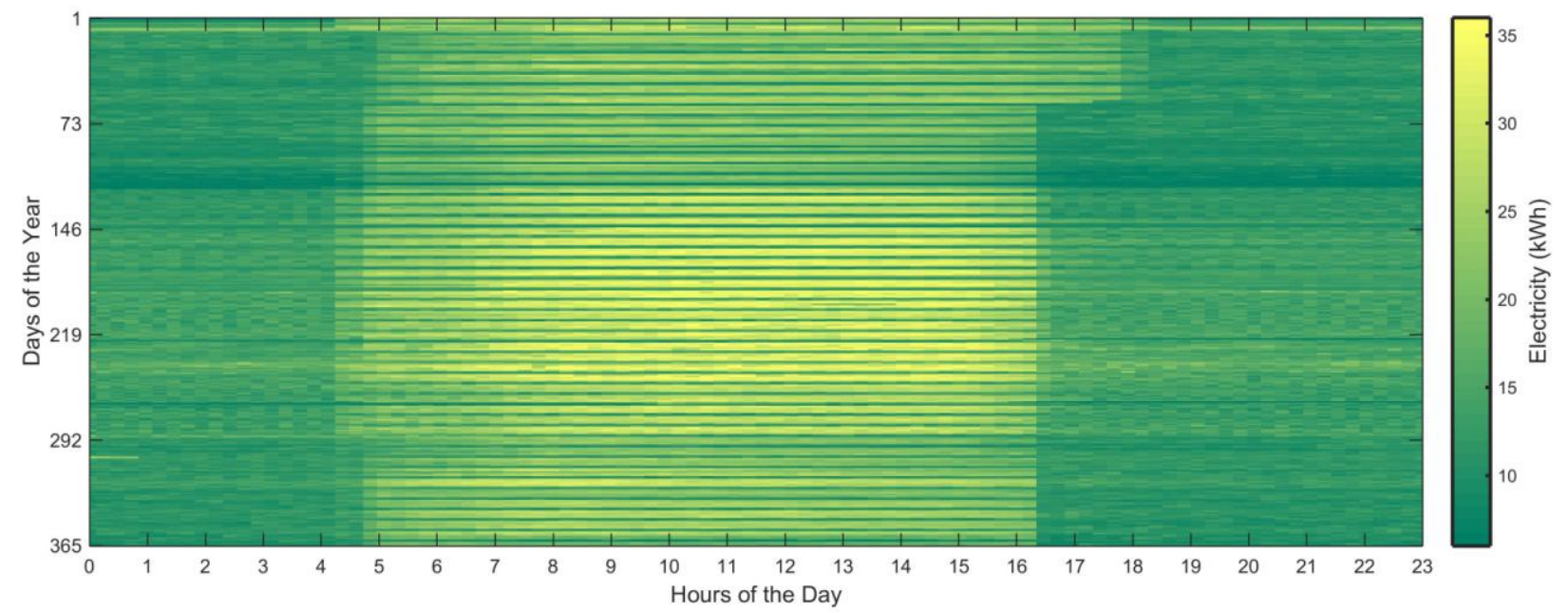

Figure 3: Electricity use patterns of the case study building in 2014

To assess accuracy of the energy simulation results, this study uses recommended metrics in ASHRAE Guideline 14, including Coefficient of Variation of Root Mean Square Error (CVRSME) and Normalized Mean Biased Error (NMBE).

$\operatorname{CVRMSE}=100 \times \frac{\left[\Sigma\left(\mathrm{y}_{\mathrm{i}}-\hat{y}\right)^{2} /(\mathrm{n}-\mathrm{p})\right]^{1 / 2}}{\bar{y}}$

$\operatorname{NMBE}=100 \times \frac{\left|\Sigma\left(\mathrm{y}_{\mathrm{i}}-\widehat{\mathrm{y}_{1}}\right)\right| /[(\mathrm{n}-1)]}{\overline{\mathrm{y}}}$

Where $y_{i}, \bar{y}, n$, and $\widehat{y}_{l}$ are the metered building energy data, the arithmetic mean of the metered building energy data, the number of observations, and the simulated building energy data, respectively. ASHRAE Guideline 14 recommends CVRSME less than 15\% and NMBE 5\% for the monthly model calibration. Overall, as Table 3 illustrates this study develops three different energy models. 
Table 3: The three developed building energy models

\begin{tabular}{|c|c|c|}
\hline Model \# & Model Name & Description of the model \\
\hline 1 & Baseline building energy model & This model is the baseline energy model from Virtual PULSE that requires \\
calibration of inputs.
\end{tabular}

\subsection{Case Study}

An urban neighborhood at the University of Maryland with the urban plan area density $\left(\lambda_{p}\right)$ of 0.22 serves as the case study. Figure 4 depicts the University of Maryland campus map with highlights in red for the building(s) of interest. Specifically, Figure 4(a) illustrates the selected urban neighborhood, and Figure 4(b) shows the four selected buildings. Three of the selected buildings are administrative offices, and one of the buildings is a recreational building. Among the selected buildings, one of the buildings highlighted in red in Figure 4(b) is selected as the primary case study building. Key factors in the selection of this primary building are (1) reliability and availability of the metered energy consumption interval data, (2) availability of detailed inputs for the building energy modeling, (3) accessibility of different locations around the case study building for on-site measurements, and (4) wind sheltering since the predominant wind direction for the duration of the experiments is in the South East direction. Overall, the ability to install temperature sensors in shaded/unshaded and previous/impervious surfaces allows to collect temperature measurements for different land covers around the building of interest.

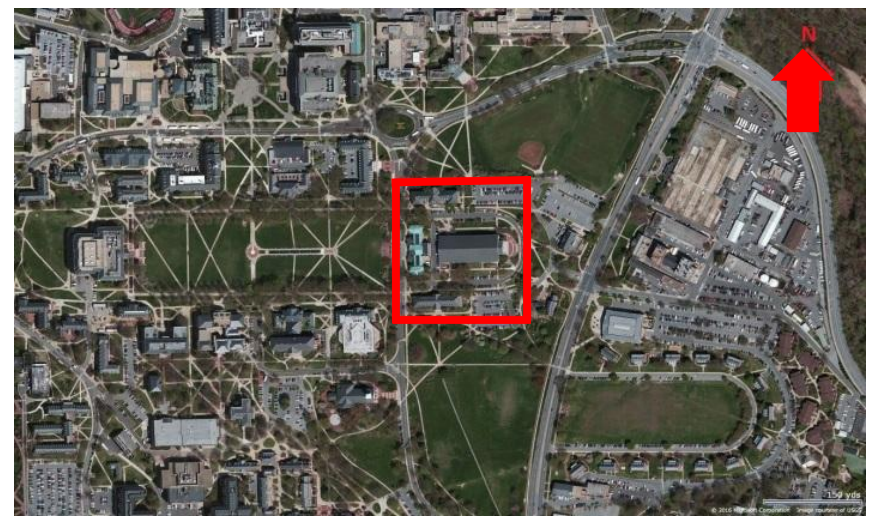

(a)

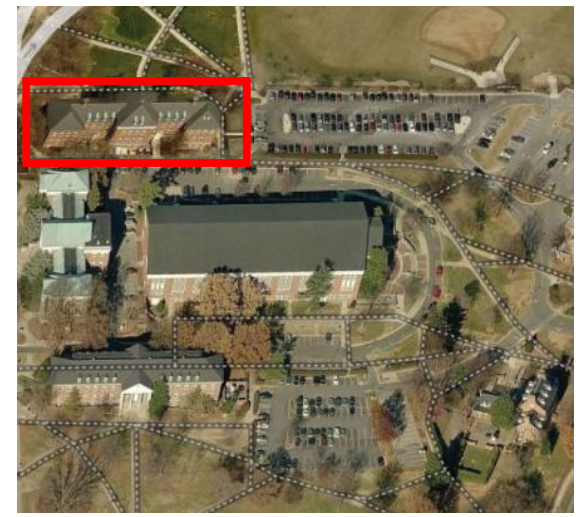

(b)

Figure 4: The selected urban neighborhood at the University of Maryland: (a) Satellite view and (b) Bird's eve view of the primary building of interest

\section{CFD Verification and Validation $(V \&$ V)}

Validation and verification of the CFD simulation results is to provide confidence in the accuracy of the simulation results [25]. This study uses two approaches to validate and verify the CFD simulation results. These two approaches are: (1) validating the outdoor air temperature for various locations around the building of interest, and (2) confirming the range of variation for y-plus with the acceptable values. These two approaches allow this study to independently validate and verify the quality of CFD simulation results. 


\subsection{Model Setup}

Consideration of the thermal boundary conditions on the building and ground surfaces are key contributing factors to the accuracy of the CFD simulation results [26]. Therefore, it is crucial to consider (i) actual weather data, and (ii) detailed solar radiation on the surfaces. For the validation study, the CFD simulations are for June 24, 2014 at 1 PM. The measured air temperature from the AMY weather data file is $28.2^{\circ} \mathrm{C}$. The domain size for the CFD simulations is $420 \mathrm{~m} \times 600 \mathrm{~m} \times 100 \mathrm{~m}$, and the size of the background mesh created by the blockMesh generator in OpenFOAM is $20 \mathrm{~m} \times 20 \mathrm{~m} \times 20 \mathrm{~m}$ cells. Besides the blockMesh generator in OpenFOAM, this study utilizes a novel strategy to refine the mesh in three different steps using snappyHexMesh utility. These three steps are (1) one rough mesh box close to the ground up to $30 \mathrm{~m}$ of height, (2) one refined mesh box compared to the rough mesh box around the studied four buildings, and (3) one additional fine box of mesh around the primary building. Figure 5 depicts the details of the meshing strategy.

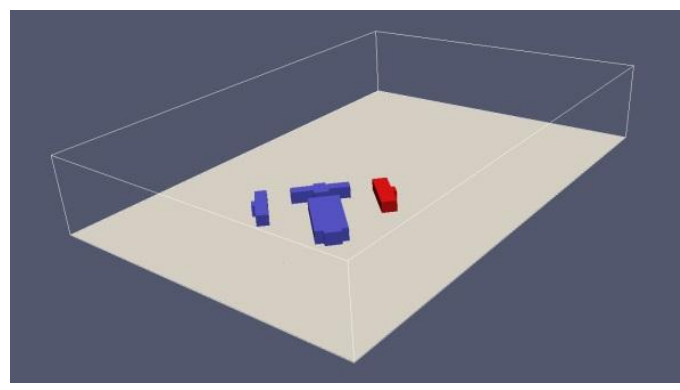

(a)

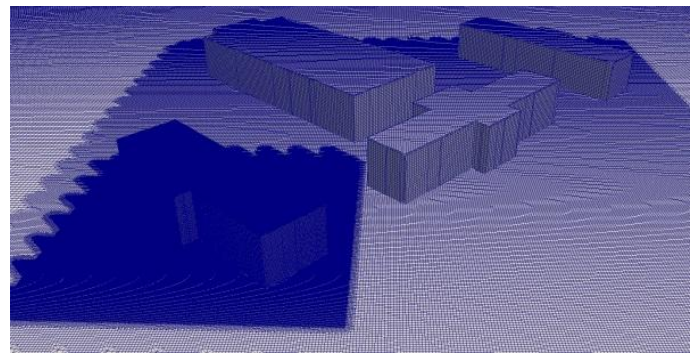

(c)

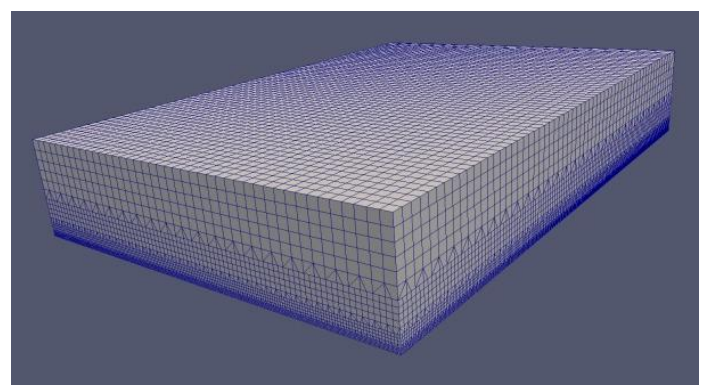

(b)

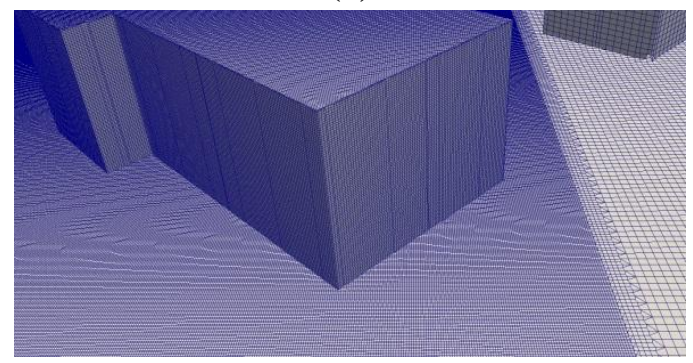

(d)

Figure 5: CFD simulation for (a) the domain including primary (red) and secondary (blue) buildings, (b) the final mesh domain and the refined mesh close to the ground, (c) secondary and primary buildings refined mesh, and (d) fine mesh at the primary building

Inlet temperature is fixed at $28.2^{\circ} \mathrm{C}$, and the inlet velocity is defined based on a profile using Atmospheric Boundary Layer (ABL). Specifically, the following Equation (9) represents the ABL equation implemented in OpenFOAM as the atmBoundaryLayerInletVelocity boundary condition [38]:

$U=\frac{U^{*}}{\kappa} \ln \frac{z-z_{g}+z_{0}}{z_{0}}$

Where $\mathrm{U}^{*}, \mathrm{z}, \mathrm{z}_{\mathrm{g}}$, and $\mathrm{z}_{0}$ are the friction velocity, the elevation above the ground, the elevation of the ground, and the roughness length of the ground, respectively. In this case study, $z_{0}$ is $0.3 \mathrm{~m}$ due to the mostly small obstacles surrounding the building of interest. The maximum inlet velocity is $5 \mathrm{~m} / \mathrm{s}$. Furthermore, the outlet pressure is set to a reference of zero, while the top and sides of the simulation domain have the slip condition that equals zeroGradiant for scalars. Currently, measurement of the solar irradiances on the building and ground surfaces is costly and infeasible at the scale of this study to capture the detailed solar irradiances on the horizontal/vertical surfaces. A remedy to capture the detailed solar irradiances is to benefit from the simulation tools and validate the simulated solar irradiances at specific locations. Therefore, Radiance simulations provided solar irradiances on the building and ground surfaces for all the patches during the time of the validation study. Figure 6 illustrates the solar 
irradiances on the building and ground surfaces. The verification and validation section considers using the Infrared (IR) images to indirectly validate the outdoor solar irradiances on the building and ground surfaces.

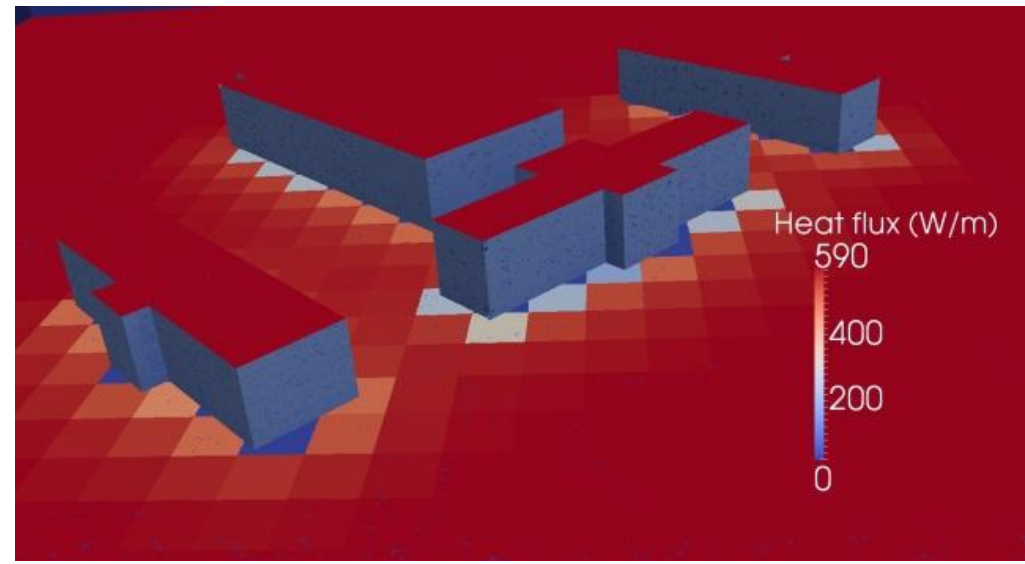

Figure 6: The simulated constant heat flux from Radiance for the validation study

\subsection{Validation of air temperatures}

The temperature validation requires measurement of the temperature values at different locations close to the building of interest. Figure 7 provides a depiction of eight locations for the on-site measurements and validation. This study utilizes a previously published methodology for the deployment of the sensors and analysis of the measured temperatures [20]. For the selected locations, iButton temperature sensors with addition of reflective aluminum coating allow measurements of outdoor air temperatures in eight different locations around the building of interest. Furthermore, in each location, three different elevations of $1 \mathrm{~m}, 1.5 \mathrm{~m}$, and $2 \mathrm{~m}$ are selected to measure temperature values. The eight spatial locations for the installation of the sensors allow selection of location within and outside of the hydraulic as well as different representation of the ground surfaces. In addition, this study selects theses elevations in order to capture the temperature variation in the thermal boundary layer close to the ground. Existing studies reported that within a $10 \mathrm{~m}$ elevation close to the ground, there are insignificant temperature variations [20, 39]. Consequently, to allow observation of near surface temperature, the area of interest where the thermal boundary layer exists and the heat transfer processes occur, this study considers $0.5 \mathrm{~m}$ elevations for the selected locations. Overall, this study acquired outdoor air temperature data in twenty-four locations. 


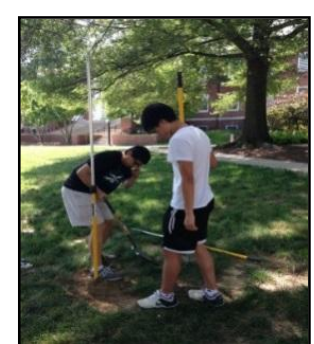

B: Shaded (Tree)

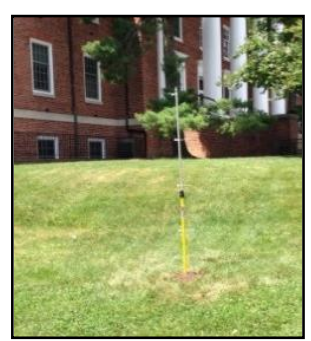

A: Unshaded (Grass)

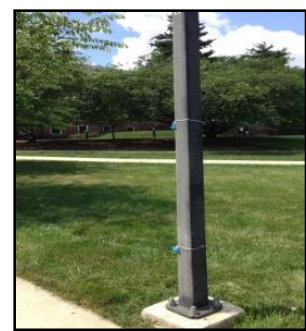

H: Unshaded (Grass/Concrete)

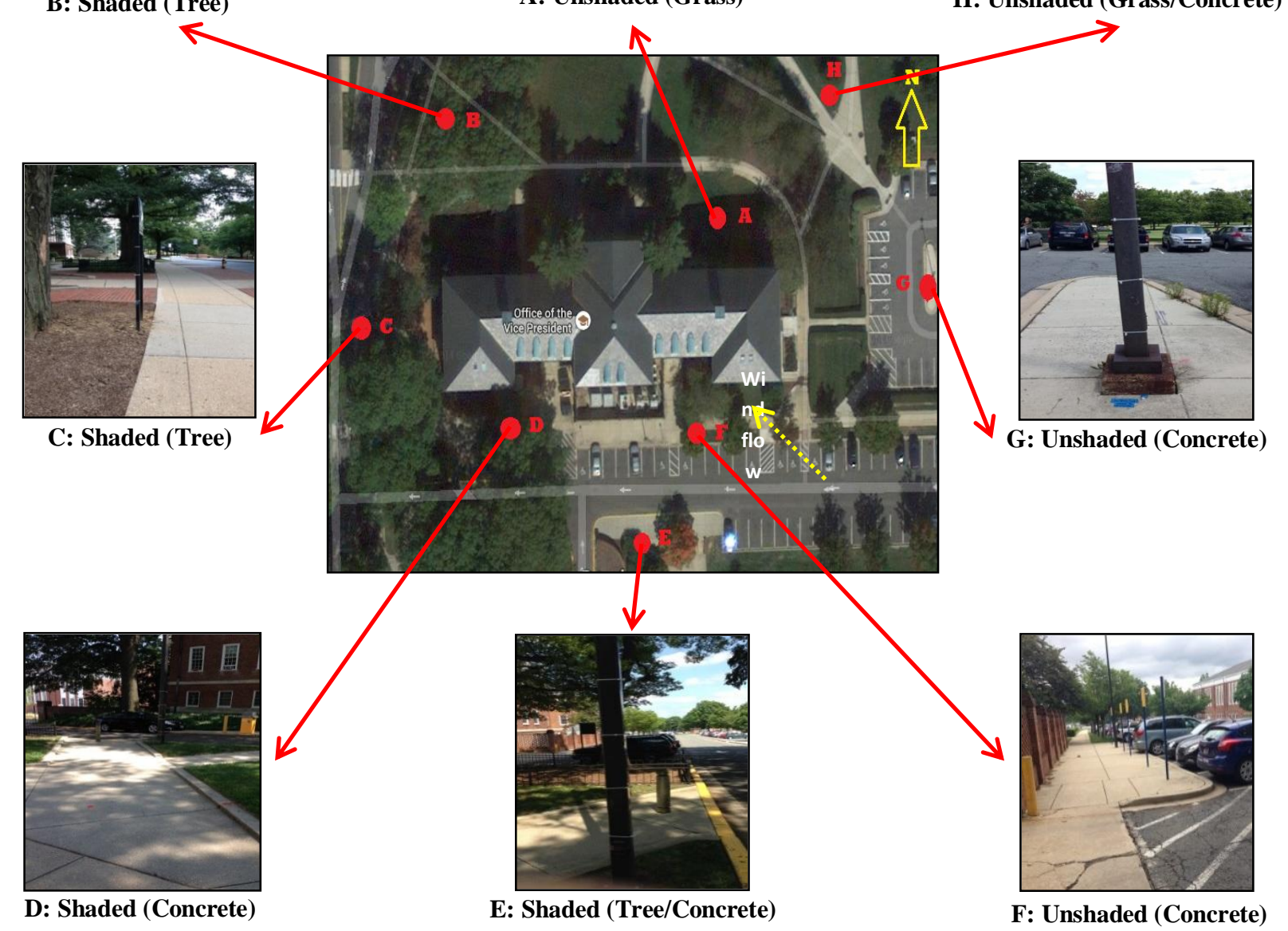

C: Shaded (Tree)
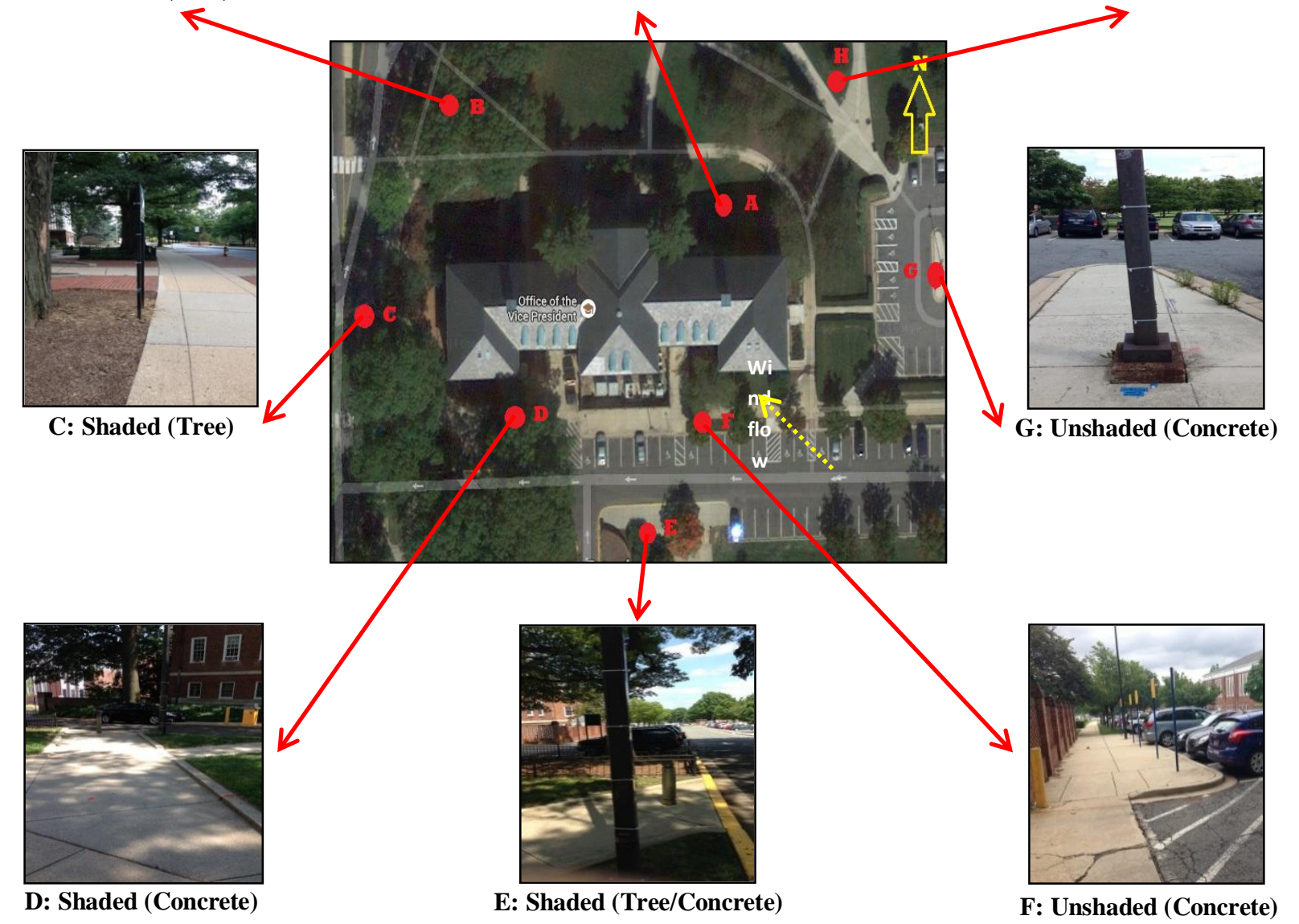

Figure 7: The selected locations for the validation study close to the building of interest

To understand local influence of a land cover, this study considers combination of shaded/unshaded and impervious/pervious surfaces for temperature data collection. While the selection of pervious surfaces entails tree and grass, the selection of the impervious surfaces includes concrete surfaces. Out of the eight measurement locations, four locations include (1) unshaded grass (A), (2) unshaded concrete (G), (3) shaded tree (B), and (4) shaded tree (E)serve as the validation locations for this study. Among the eight locations, the selected four locations have reliable temperature measurements for all three elevations of $1 \mathrm{~m}, 1.5 \mathrm{~m}$, and $2 \mathrm{~m}$. Therefore, the selected locations provide best data points for the validation study compared to the other locations.

Outdoor air temperature and solar radiation influences accuracy of the simulated results. Therefore, this study considers three different times during a day, including (i) early morning represented with 8 AM, (ii) mid-day represented with $12 \mathrm{PM}$, and (iii) late afternoon represented with $6 \mathrm{PM}$ with for the validation. Figure 8 depicts the temperature readings and CFD simulation results at $12 \mathrm{PM}$ as a function of the elevation for three different elevations of $1 \mathrm{~m}, 1.5 \mathrm{~m}$, and $2 \mathrm{~m}$ for the four selected locations. Outdoor air temperature and solar radiation are 594 $\mathrm{W} / \mathrm{m}^{2}$ and $28.3^{\circ} \mathrm{C}$ at $12 \mathrm{PM}$. Similarly, Table 4 provides the measured and simulated temperature readings with the 
associated air temperature and solar radiation during the 8 AM and 6 PM validation time. As the existing guidelines show, verification and validation could support credibility of the simulations and minimize the levels of uncertainty and error $[31,40]$. The two dashed lines in Figure 8 represent the measurement accuracy of $\pm 0.5^{\circ} \mathrm{C}$ for iButton temperature readings. This study uses the framework used in the literature to compare the simulation results with the measurements, requiring to consider the variation of the measured temperature readings within the total accuracy of the sensors $[25,41]$. The comparison between measured and simulated temperatures confirm that the simulation results are within the accuracy of the measurements except for the two highest elevations $(2.0 \mathrm{~m})$ in the shaded area marked as point $\mathrm{B}$ and $\mathrm{E}$ in Figure 7. For these two elevations, the simulated temperatures are close to the range of sensor accuracy. The discrepancies between the results of the simulations and measurements of the $2.0 \mathrm{~m}$ in the shaded area marked as point B and E might be associated with the representation of the pervious surfaces. The results of Table 4 also indicate the point B results require careful consideration. Therefore, to improve quality of the simulated temperatures for these two points, future studies could benefit from a better representation of the pervious surfaces compared to the current version of the representation. Due to the challenges associated with modeling outdoor airflow especially near surface outdoor air temperature, a Coefficient of Variation of Root Mean Square Error (CVRSME) for all the measure locations could provide a confidence on the results. Overall, the overall CVRSME for the 36 locations is $2 \%$, indicating most of the CFD simulation results fall within the accuracy of the measured temperatures. This validation study is unique in terms of considering a complex validation of the near surface temperatures, which extends the current state-of-the-art for the outdoor airflow validation studies. The results of this validation study suggest that the mesh near building walls is sufficiently fine, leading to accurate simulated temperature readings.

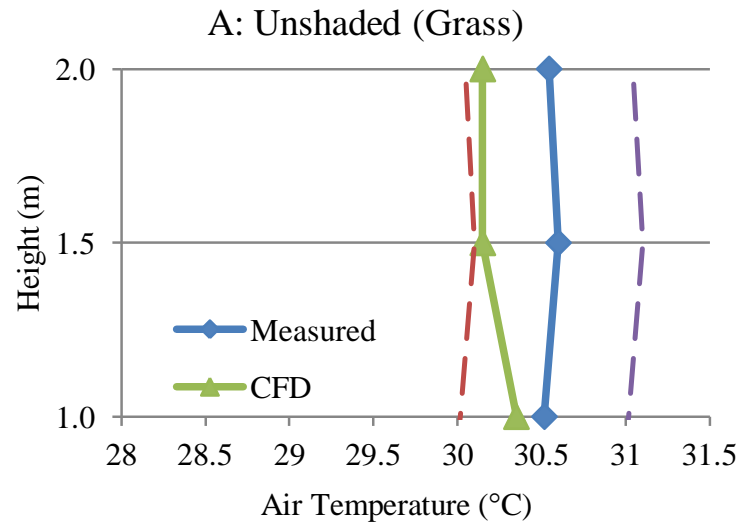

(a)

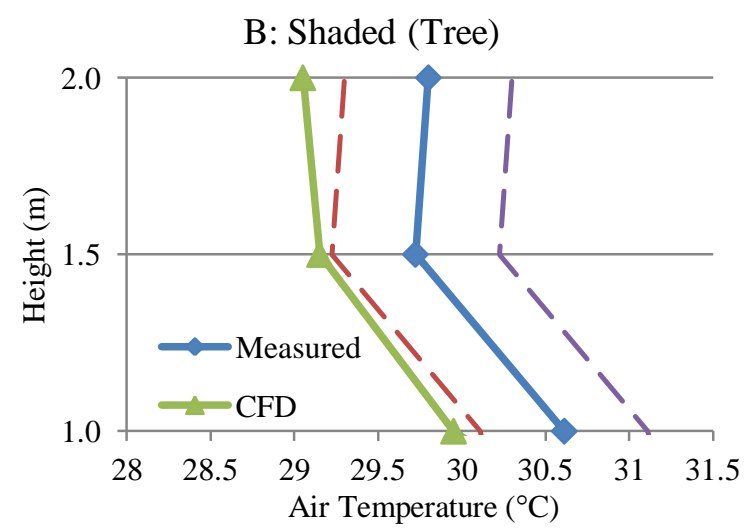

(c)

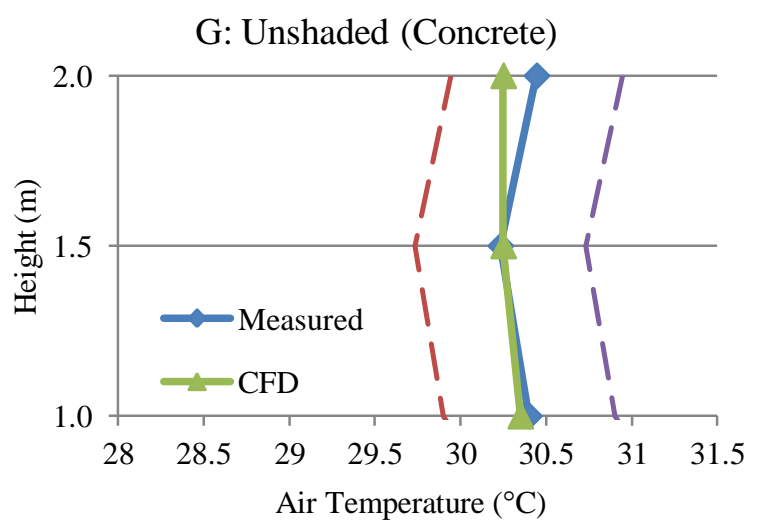

(b)

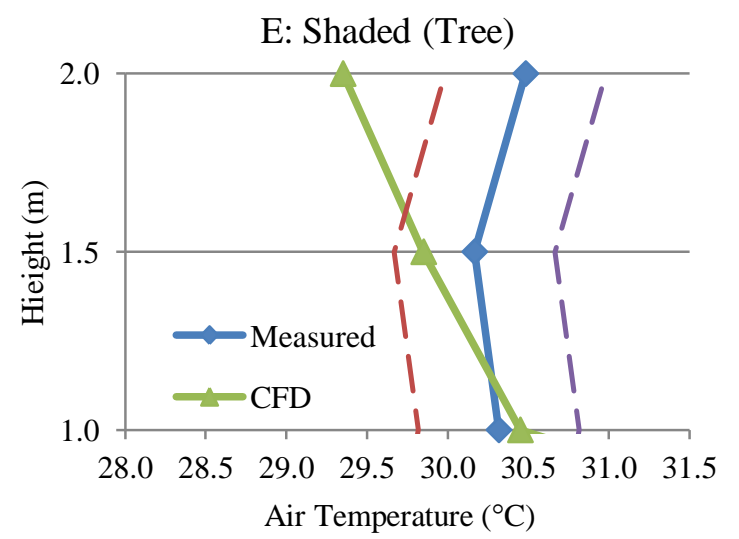

(d)

Figure 8: The measured and CFD simulation results at four locations (Note: Dash lines represent the temperature sensor accuracy range) 
Table 4: Comparisons between the measured and simulated temperatures at different locations and times

\begin{tabular}{|c|c|c|c|c|c|}
\hline Date Time & $\begin{array}{c}\text { Temperature }\left({ }^{\circ} \mathbf{C}\right) \text { Solar } \\
\text { Radiation }\left(\mathbf{W} / \mathbf{m}^{2}\right)\end{array}$ & Location & Elevation (m) & $\begin{array}{c}\text { Measured } \\
\text { Temperature }\left( \pm 0.5^{\circ} \mathbf{C}\right)\end{array}$ & $\begin{array}{c}\text { Simulated } \\
\text { Temperature }\left({ }^{\circ} \mathrm{C}\right)\end{array}$ \\
\hline \multirow{13}{*}{$\begin{array}{c}24 / 6 / 2014 \\
8 \mathrm{AM}\end{array}$} & \multirow{13}{*}{$\begin{array}{c}22.6^{\circ} \mathrm{C} \\
320 \mathrm{~W} / \mathrm{m}^{2}\end{array}$} & \multirow{3}{*}{ Location A } & 1 & 24.7 & 24.3 \\
\hline & & & 1.5 & 24.3 & 24.2 \\
\hline & & & 2 & 24.4 & 24.2 \\
\hline & & \multirow{3}{*}{ Location B } & 1 & 22.9 & 23.8 \\
\hline & & & 1.5 & 22.8 & 23.4 \\
\hline & & & 2 & 22.7 & 23.3 \\
\hline & & \multirow{3}{*}{ Location E } & 1 & 24.4 & 24.4 \\
\hline & & & 1.5 & 23.7 & 23.6 \\
\hline & & & 2 & 23.5 & 23.4 \\
\hline & & \multirow{4}{*}{ Location $\mathrm{G}$} & 1 & 24.2 & 23.9 \\
\hline & & & 1.5 & 23.7 & 23.9 \\
\hline & & & 2 & 23.7 & 23.9 \\
\hline & & & 2 & 30.4 & 30.3 \\
\hline \multirow{12}{*}{$\begin{array}{c}24 / 6 / 2014 \\
4 \mathrm{pm}\end{array}$} & \multirow{12}{*}{$\begin{array}{c}32.3^{\circ} \mathrm{C} \\
846 \mathrm{~W} / \mathrm{m}^{2}\end{array}$} & \multirow{3}{*}{ Location A } & 1 & 33.0 & 33.5 \\
\hline & & & 1.5 & 32.7 & 33.4 \\
\hline & & & 2 & 32.9 & 33.3 \\
\hline & & \multirow{3}{*}{ Location B } & 1 & 30.1 & 32.1 \\
\hline & & & 1.5 & 30.0 & 31.5 \\
\hline & & & 2 & 30.8 & 31.3 \\
\hline & & \multirow{3}{*}{ Location E } & 1 & 31.8 & 32.2 \\
\hline & & & 1.5 & 31.1 & 31.6 \\
\hline & & & 2 & 31.0 & 31.4 \\
\hline & & \multirow{3}{*}{ Location G } & 1 & 33.0 & 32.5 \\
\hline & & & 1.5 & 32.9 & 32.5 \\
\hline & & & 2 & 33.1 & 32.6 \\
\hline
\end{tabular}

Besides the temperature measurements, this study conducts performing thermography to capture spatial and temporal variation on the building surfaces. The IR images from the thermography study provide another indicator for the validation of the surface temperatures, allowing to indirectly validate the Radiance results depicted in Figure 6 [20]. This study used FLIR E40 camera with ability to capture $160 \times 120$ pixels images and measure temperature readings of less than $0.07{ }^{\circ} \mathrm{C}$ thermal sensitivity and $2 \%$ accuracy [42]. The used camera performs in the wavelengths of 8-14 $\mu \mathrm{m}$, which renders this camera suitable for temperature measurements of 0 to $100{ }^{\circ} \mathrm{C}$. Figure 9 shows the IR images for the primary locations and associated CFD temperature values. Due to the wide range of temperature variations, the IR images cannot have similar temperature ranges. Therefore, the images include statistical metrics, including minimum, average, and maximum, values to show the exact temperature values. Although as Figure 8 illustrates, except few locations especially in the shaded areas, the comparison shows that the CFD simulation predicts the temperature field fairly well for the time of experiment. Validation of the surface temperature values from the CFD with the measurements provide confidence on the accuracy of the simulated solar irradiances on the building and ground surfaces. Overall, the comparison confirms that the results are within the acceptable range for the scale of simulations conducted in this study. 


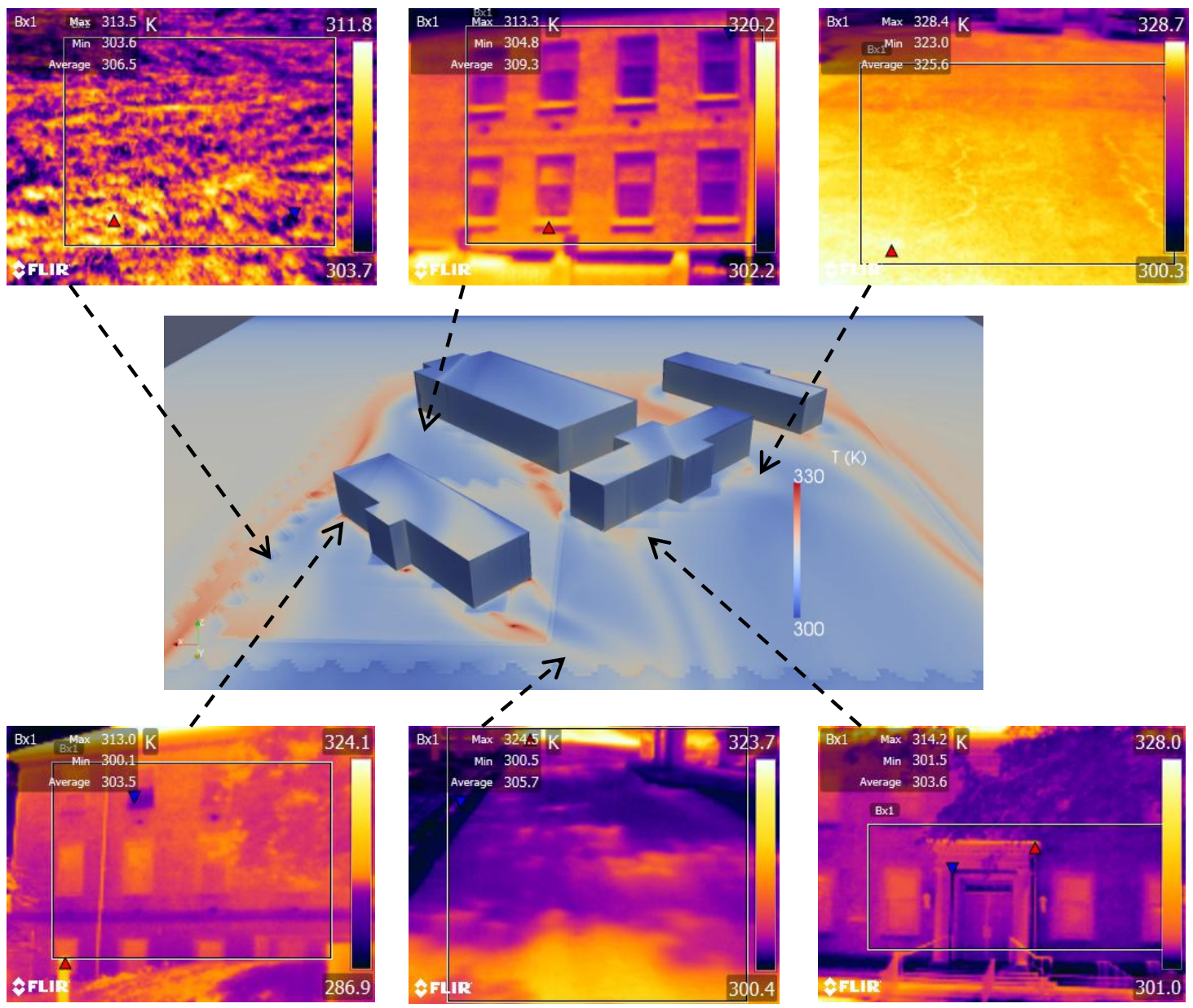

Figure 9: The IR images for the indirect validation of the building and ground surfaces

\subsection{Validation of y-plus values}

Accuracy of the CFD simulations, especially for the heat and mass transfer processes, depend on the quality of mesh near the boundary surfaces represented by a factor named y-plus $(y+)$. Y-plus represents the distance between the wall surfaces to the first mash cell adjacent to the wall. The assessment of y-plus is to verify that the generated mash is appropriate for the CFD simulations of studied buildings. The range of variation for $y+$ for outdoor airflow simulations is a function of the turbulence model and wall functions. Current studies recommend $y+$ in the range of 30 to 300 using standard logarithmic wall functions for the building surfaces located in a turbulent boundary layer $[1,20]$. Based on the circumstances, including the neighborhood size, CFD domain size, size of the cells within the proximity of the buildings, convergence, and computational resources, it is possible to justify extend the range of yplus values to $1500[43,44]$. Except the around the building of interest, the remaining surfaces could benefit from a higher y-plus and coarser mesh compared to the surfaces representing the primary case study building [1, 44, 45]. The y-plus values of this study fall into the range of less than 300 for all buildings and their surfaces in the simulation domain. One benefit of using OpenFOAM is its automated ability to report the y-plus for all of the patches.

OpenFOAM enables users to relatively easily manage the meshes and create refined mesh by defining the fine mesh volumes with a distance from the surface of a solid object or with a box. This study uses both of the mesh refinement approaches for three refinement regions to improve quality of the mesh. As Figure 5(c) depicts, the three 
refinement regions are: (i) a region away from the building of interest, (ii) a region close to the selected buildings in the neighborhood, and (iii) a region close to the building of interest. For the mesh refinement, Figure 10 shows that the difference between Case 1 and Case 2 is the alignment of the refined region close to the primary case study building. While in Case 1shown in Figure 10(a), the mesh refinement volume is not aligned to the incoming wind direction, in Case 2 shown in Figure 10(b), the mesh refinement volume is aligned with the incoming wind direction. As it is shown in Figure 10(c), the use of Case 2 with level 7 of refinements, and Case 1 with level 6 of refinement results in the acceptable range of y-plus $\left(y^{+} \approx 300\right)$ depicted with a horizontal red line. The median y-plus values for both cases are close to 300. Therefore, the results of the y-plus analysis indicate that the deployed mesh near the building solid surfaces is of good quality. Overall, this study utilized two different approaches to validate and verify the quality of the CFD simulation results. The validation study suggests that the CFD simulations are accurate, and the verification study shows that the mesh near building walls is sufficiently fine. Using the validated and verified CFD setup, this study further develops the wind multipliers in the next step.

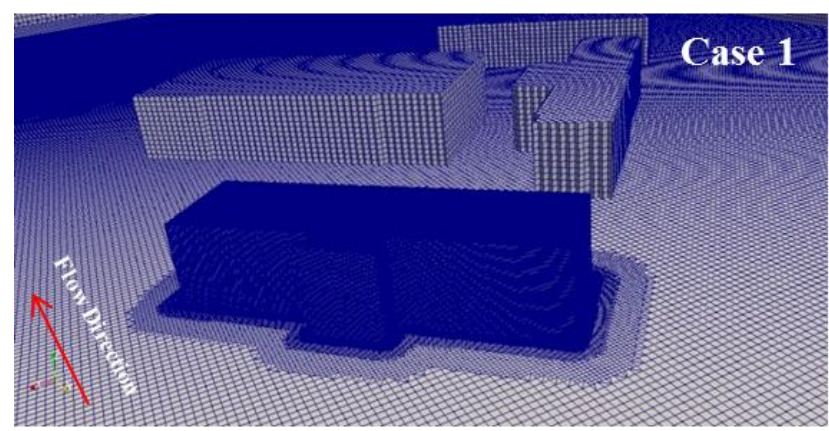

(a)

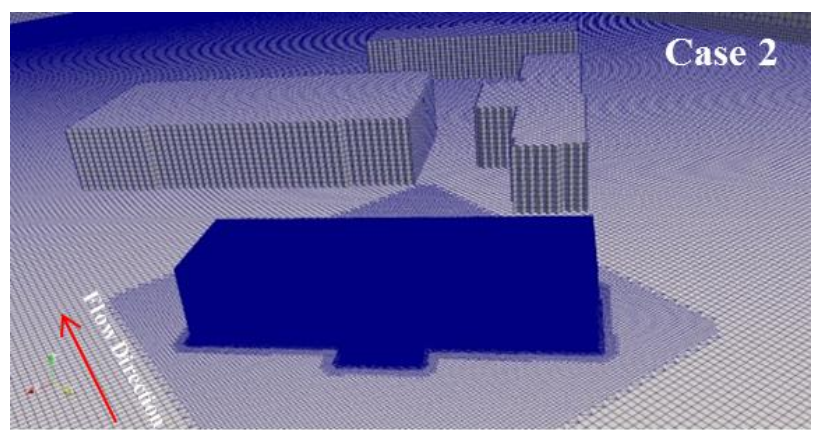

(b)

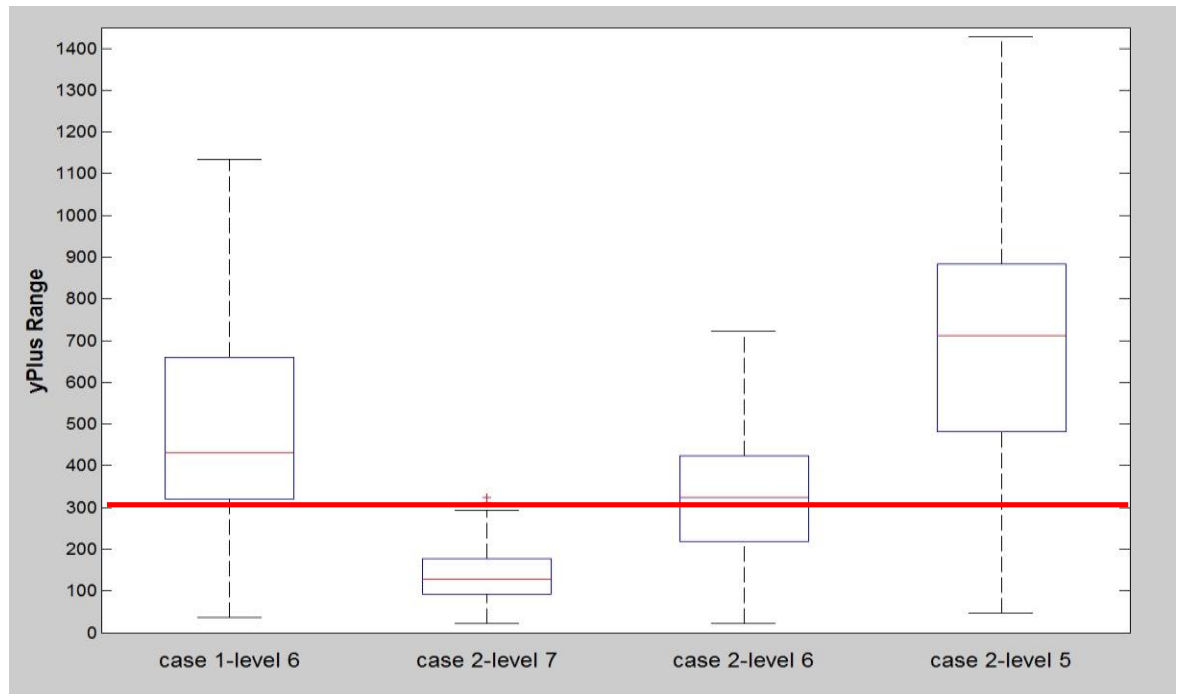

(c)

Figure 10: (a) Case 1 method using a confined region close to the building with mean $y+$ of 489, (b) Case 2 using the distance method mesh refinement with mean $y+$ of 327 , and (c) the boxplot to compare the $y+$ values for the surface patches

\section{Calibrated Energy Model Results}

Using the infiltration coefficients designed to include impacts of urban neighborhood, represented by Equation (6), enabled this study to consider the influence of the wind speed variations as well as the temperature variations for the infiltration rates in the building energy models. With the adjustments in the weather data file and infiltration model 
coefficients in the baseline building energy model, EUI (Energy Utilization Index) of the building is $228.4 \mathrm{kWh} / \mathrm{m}^{2}$, a value close to the actual metered 2014 EUI of $237.2 \mathrm{kWh} / \mathrm{m}^{2}$. Figure 11 and Figure 12 illustrate the monthly electricity and steam consumptions for two years, 2013 and 2014. It is important to note that the metered steam consumptions during the summer seasons are not accurate due to the malfunction in the meter readings. Therefore, this study confirms quality of the data for other months with the University of Maryland Facilities Management and considers the two years data excluding summer consumptions from June to August. To calibrate the modeling of steam consumptions besides using the new infiltration coefficients, this study reviewed the interval steam consumptions and building controls data. This review results in a change of the cooling setpoint temperature from $23.9^{\circ} \mathrm{C}$ to $25.5^{\circ} \mathrm{C}$ and the building occupied hours from $8 \mathrm{AM}-10 \mathrm{PM}$ to $6 \mathrm{AM}-4 \mathrm{PM}$. Table 5 provides CVRSME and NMBE for the baseline and adjusted models. For the calibration of the heating consumption, his study assumes heating season occurs from October to March. The results of the CVRSME and NMBE meet the requirements of the monthly calibration. Based on the recommendations in the ASHRAE Guideline 14, the CVRSMEs and NMBEs are less than $15 \%$ and $5 \%$ respectively.

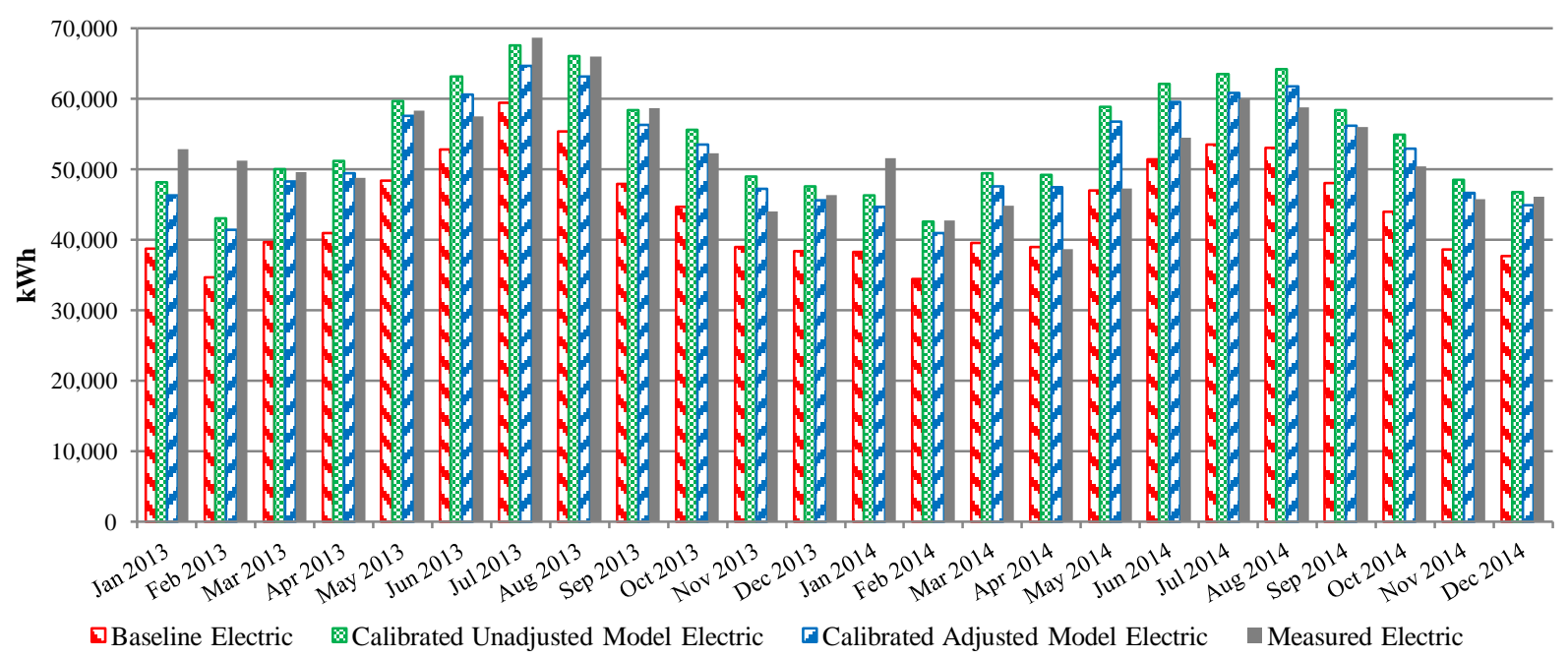

Figure 11: The measured, baseline, and adjusted model results of monthly electricity comparison for 2013 and 2014

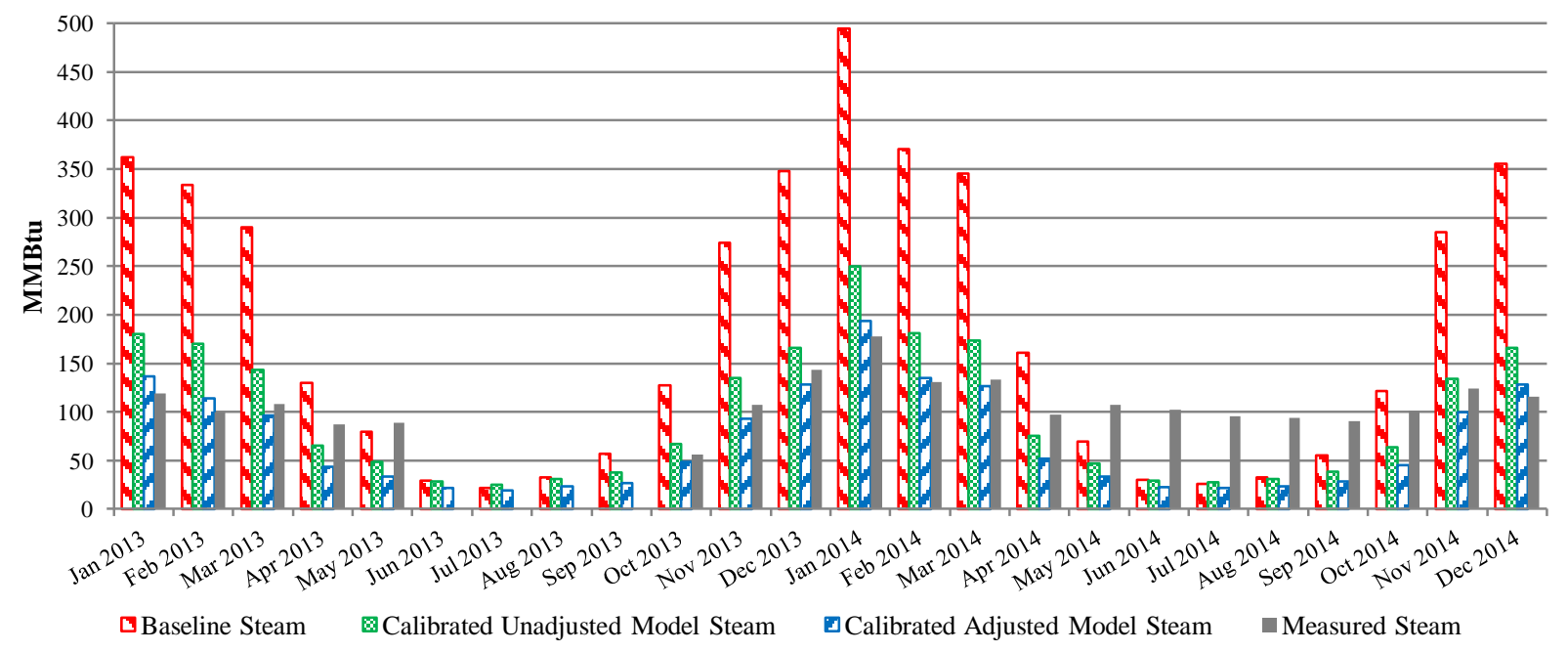

Figure 12: The measured, baseline, and adjusted model results of monthly steam comparison for 2013 and 2014

Table 5: Summary of CVRSME and NMBE as the calibration indices 


\begin{tabular}{|l|l|l|l|l|}
\hline Utility & Index & Baseline model & Calibrated model & Acceptable range \\
\hline \multirow{3}{*}{ Electricity } & CVRMSE & $17 \%$ & $9 \%$ & Less than $15 \%$ \\
\cline { 2 - 5 } & NMBE & $15 \%$ & $0 \%$ & Less than $5 \%$ \\
\hline \multirow{2}{*}{ Steam } & CVRMSE & $168 \%$ & $46 \%(14 \%$ heating $)$ & Less than $15 \%$ \\
\cline { 2 - 5 } & NMBE & $108 \%$ & $23 \%(1 \%$ heating) & Less than $5 \%$ \\
\hline
\end{tabular}

An important implication of the calibrated building energy model using the adjusted weather data developed with the wind multipliers is to determine distribution of the building loads. While the building energy simulations using the unadjusted weather file for College Park results in an EUI of $247.3 \mathrm{kWh} / \mathrm{m}^{2}$, the adjusted AMY 2014 weather data with the wind multipliers results in an EUI of $228.4 \mathrm{kWh} / \mathrm{m}^{2}$. The adjusted weather data caused a decrease of more than 5\% in the total EUI of the building. One important point about this wind effect is that even the 5\% impact on EUI can be the difference between a calibrated vs. an uncalibrated model. However, more importantly, is the energy consumption and load patterns of the building when the building model is calibrated and when the building model is not calibrated.

\section{Wind Multipliers}

This study develops wind multipliers in the eight principal wind directions for the weather data files. Figure 13 illustrates three steps in the development of wind multipliers. In the first step, this study conducts isothermal CFD simulations for the incoming wind velocity of $1 \mathrm{~m} / \mathrm{s}$ in eight principal directions, including N, NE, E, SE, S, SW, W, and NW, and calculates the resultant wind velocities at the windward facade of the primary case study building. Current studies consider flow around buildings within the urban neighborhood within the range of $5 \times 10^{-5}$ to $5 \times 10^{-6}$ and quantify the impact of wind direction [17, 46, 47]. Therefore, this study selects these eight principal directions and incoming velocity of $1 \mathrm{~m} / \mathrm{s}$. The selection of an incoming velocity of $1 \mathrm{~m} / \mathrm{s}$ ensures a Reynolds number of $10^{-6}$, representing a turbulent flow regime. Consideration of $1 \mathrm{~m} / \mathrm{s}$ allows providing a simple approach to recall the wind multipliers as long as the characteristics length provides a turbulent flow regime. Otherwise, the framework requires to use another incoming velocity that represents a turbulent flow for the outdoor CFD simulations. The second step calculates the wind multipliers by dividing the averaged wind velocity in front of the windward façade with the incoming wind velocity of $1 \mathrm{~m} / \mathrm{s}$. The third step adjusts the wind velocities for each direction based on the developed eight principal wind multipliers. 
Step 1:

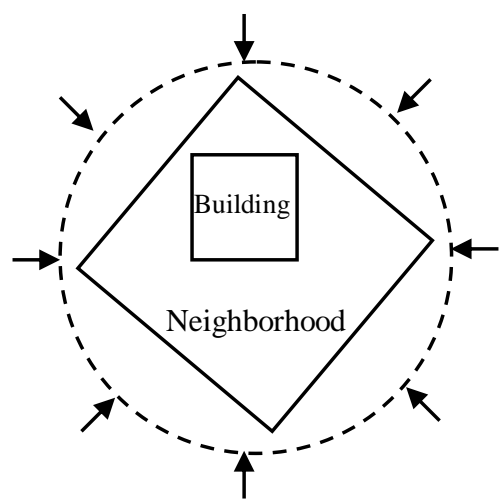

- 8 CFD cases for $1 \mathrm{~m} / \mathrm{s}$ wind in the principal directions
Step 2:

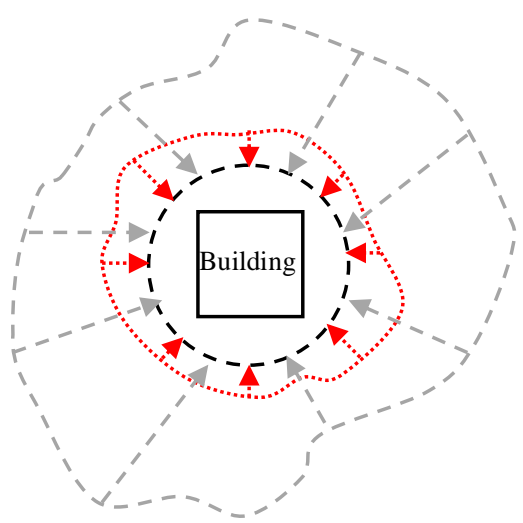

- Wind multiplier calculations

Step 3:

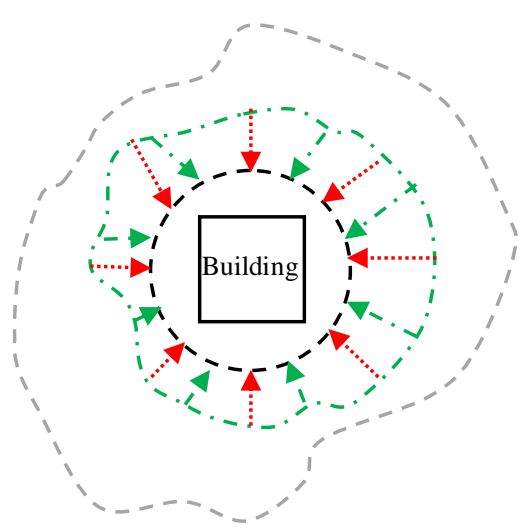

- Adjusted wind velocities

Adjusted wind velocity
in weather data file

Figure 13: The steps performed to calculate the wind multipliers and their deployment in the weather data file

The averaged wind velocity in front of the windward façade is based on the CFD simulation results at $5 \mathrm{~m}$ in front of the exterior façade and $10 \mathrm{~m}$ above the ground. This approach is to collect the wind data outside the boundary layer of the case study building. The selection of $10 \mathrm{~m}$ above the ground for the wind speed collections is similar to the wind speed measurements of typical weather stations. Figure 14 illustrates the CFD simulation setup close to the building of interest and the horizontal lines for the wind velocity data extraction from the CFD results.

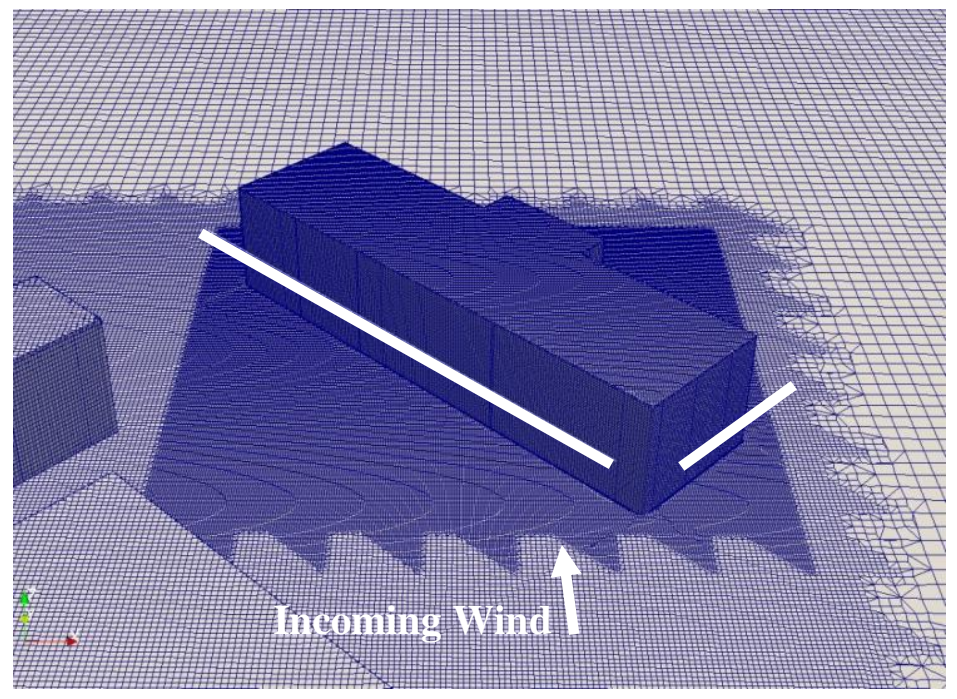

Figure 14: Representation of the wind velocity data averaging at the windward façade represented by the two white lines at $5 \mathrm{~m}$ in front of the building and 10 above the ground in the CFD simulation domain

The required steps to create wind multipliers are: 
1. Create isothermal CFD simulations using simpleFOAM solver

2. Select incoming wind velocity of $1 \mathrm{~m} / \mathrm{s}$

3. Consider appropriate windward surfaces

a. When the incoming wind has an angle of 45 degree, the windward façade includes the two building walls as shown in Figure 14.

b. For the cases when the wind direction is not 45 degree, this study only considers one windward façade.

4. Average calculated wind velocities on the windward façade and divide them by the inlet velocity.

5. Use the developed wind multipliers for the wind velocities in the input weather data file for energy models.

The wind multipliers in each direction are the averaged value of data collected in front of the building of interest. Figure 15 illustrates the calculated wind multipliers in a wind rose chart. The wind multiplier results indicate that the highest wind velocities on the building occur in the East and West directions, and lowest wind velocities on the building are in the North and South directions. This result is predictable since there are no buildings around the East and West side of the building of interest. Overall, the results of wind multiplier depicted in Figure 15 shows wind multipliers can vary significantly based on the direction from 0.4 in the South to 0.8 in the East direction. Importantly, the wind multipliers could reflect a local wind channeling in urban canyons by having values greater than 1.

The next step after the calculation of wind multipliers is to prepare the input weather data files for the energy modeling. This study multiplies the wind velocities at each hour in the AMY weather data for College Park, MD for 2013 and 2014 using the calculated wind multiplier in Figure 15. Because the wind multipliers are developed for 8 principal directions, the potential error in the calculation of adjusted wind velocity is highest at 22.5 degrees from the principal directions. After adjusting the wind velocity column in the AMY weather data, there is a new weather data file named "Adjusted Weather File".

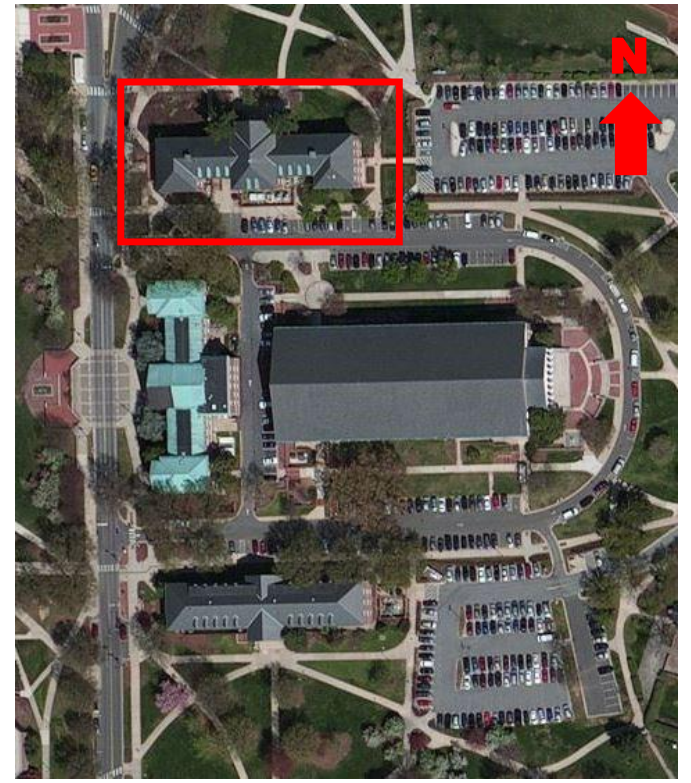

(a)

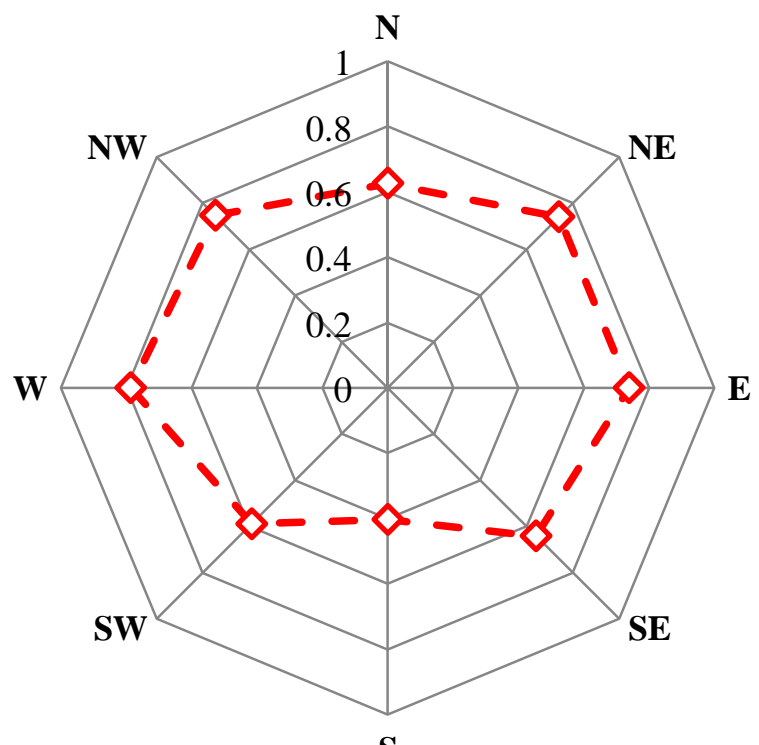

$\mathbf{S}$

(b)

Figure 15: (a) The building of interest highlighted in the red box, and (b) the calculated wind multipliers 


\section{Calibrated Adjusted Building Energy Model Results}

This study utilizes the results of the wind multipliers to adjust the weather data. One of the important impacts of the wind multipliers is on the infiltration rate in the building energy models. An important implication of the calibrated building energy model using the adjusted weather data developed with the wind multipliers is to determine distribution of the building loads. While the building energy simulations using the unadjusted weather file for College Park results in an EUI of $247.3 \mathrm{kWh} / \mathrm{m}^{2}$, the adjusted AMY 2014 weather data with the wind multipliers results in an EUI of $228.4 \mathrm{kWh} / \mathrm{m}^{2}$. The adjusted weather data caused a decrease of more than $5 \%$ in the total EUI of the building. One important point about this wind effect is that even the 5\% impact on EUI can be the difference between a calibrated vs. an uncalibrated model. However, more importantly, is the energy consumption and load patterns of the building when the building model is calibrated and when the building model is not calibrated.

Figure 16 shows the peak cooling and heating sensible heat gain patterns in terms of heat rejection or the heat removal in different categories with the adjusted and unadjusted weather data files in 2014. The energy conservation law requires that the sum of all the heat gains equals to the sum of the heat losses. A comparison between the results with adjusted and unadjusted weather data files shows that equipment, people, and lighting represent only heat additions, and their patterns do not change with the use of different weather data files as expected. Furthermore, these end-uses are a function of the building area and/or number of people, rather than being directly related to the weather. Changes in the wind velocity have an influence on the conduction, infiltration, window heat gains/losses, and HVAC. Changes in the heat removal through conduction and windows are partly associated with the changes in the convective heat transfer coefficients. The most significant variation among the end-uses occurs for the infiltration rates. Changes in the wind velocity of the weather data files significantly change the heat removal and heat rejection by infiltration. This decrease in infiltration contribution is more significant in the heat removal mostly taking place in winter than the heat addition mostly taking place in summer. It is important to note that both heat removal and heat addition can occur at any time of the year. For example, infiltration heat removal could occur in heating months, early evenings, or early mornings in summer months when the outside air is colder than the indoor air. The deployed and calibrated energy model is able to capture those occurrences.

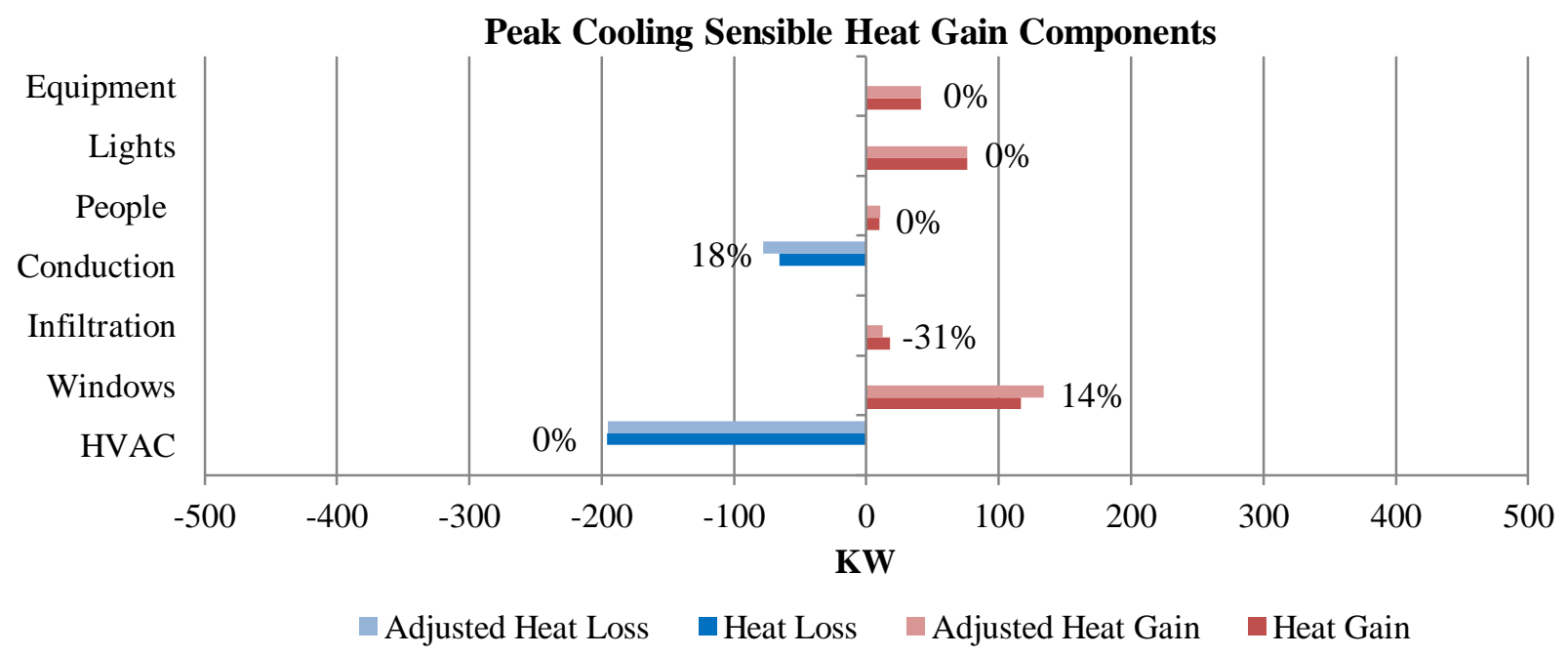

(a) 


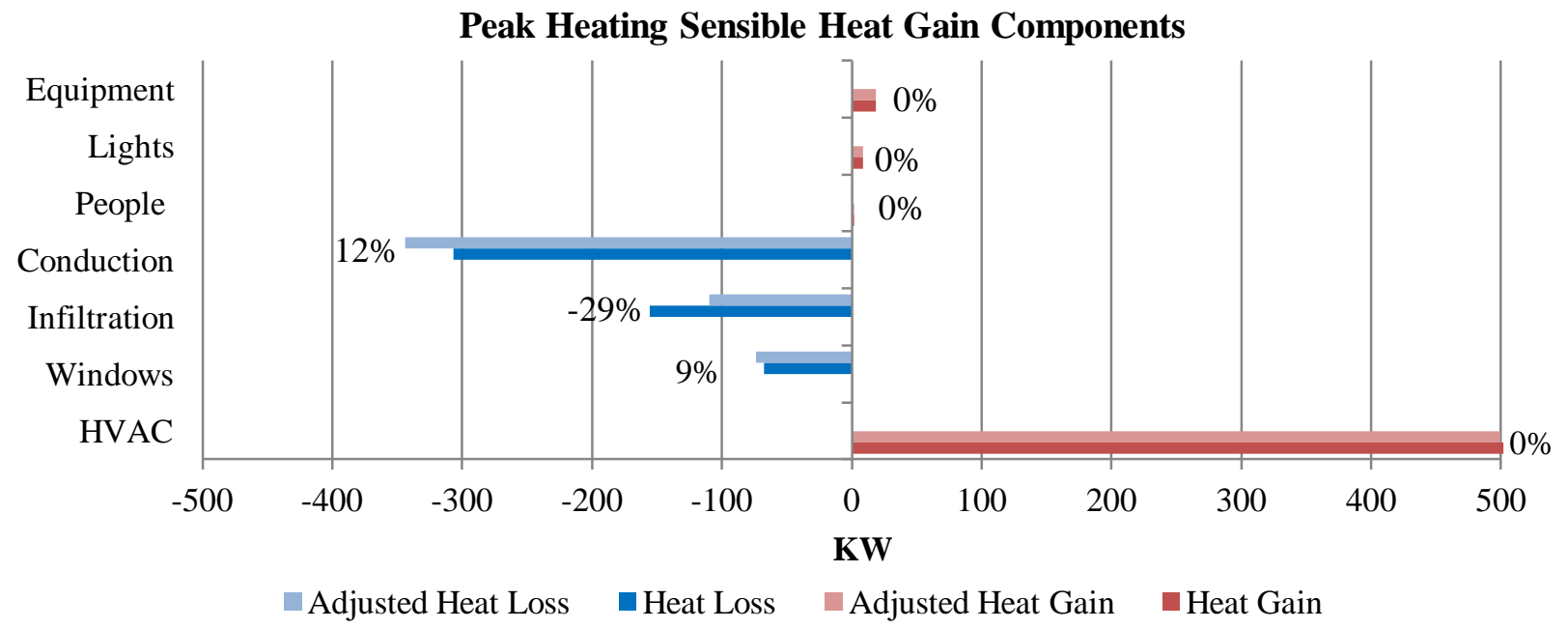

(b)

Figure 16. A comparison between (a) peak cooling sensible cooling load and b) peak heating sensible load patterns with adjusted and unadjusted weather data files in 2014

The results of Figure 16(a) show that the adjusted weather data resulted in about $31 \%$ reduction in infiltration heat gain and heat loss for peak sensible heat gain components. As Figure 16(b) shows at the peak heating loads, using the adjusted weather reduces infiltration heat loss by $29 \%$. This reduction in heat loss at peak heating is replaced with an increase in mainly conduction and windows heat removals. For the cooling seasons, heat removal mechanisms at the building enclosure, especially infiltration, have a lower overall impact on the total HVAC cooling load. However, the reduction in infiltration heat gain is accompanied with an increase in windows heat gain and an increase in conduction heat loss. The lower wind velocities in the studied neighborhood led to lower infiltration rates but higher heat gain or heat loss through surface conduction and windows. Overall, the changes in the heat gains and heat losses due to conduction, windows, and infiltration lead to minor change in the HVAC peak heating or cooling loads.

\section{Discussions}

The results of this study have implications on the design of new and retrofit of existing buildings located in urban neighborhoods. To account for the influence of actual wind velocities on these buildings, there is a need to use appropriate coefficients for infiltration models as well as adjust wind velocities using local wind multipliers. Currently, the building energy models do not account for the accurate representation of the infiltration models based on the effect of urban neighborhood. The results of this study indicate the heat gain patterns change significantly with the suggested modifications on the wind multipliers. Although the results showed only $5 \%$ change in the total EUI of the building, the energy consumption patterns confirmed a significant changes in the heating and cooling demands on the HVAC system. Therefore, a calibration process for building energy modeling requires taking into the account local wind effects. For example, the implementation of developed wind multipliers showed a direct effect on the infiltration rates in the building energy models. Furthermore, the results of this study also have indirect implications on the modeling the convective heat transfer coefficients in the building energy models since the wind velocity is a key factor in the forced convection [18, 20,48]. Future studies could utilize the wind multipliers in the CHTCs to develop urban neighborhood-based CHTCs. It is important to notice that the current study developed linear wind multipliers. One could assess impacts of considering non-linear correlations and quantify the impacts of different correlations.

The validation case study followed a previously developed methodology to validate the simulated temperature results with the on-site temperature measurements $[20,25]$. The validation of the simulated temperatures shows that 
they are within the accuracy of the deployed sensors. Future studies could aim to validate both temperatures and wind velocities in order to consider both the thermal and hydraulic boundary layers. It is important to note that the velocity measurements require installation of sensors, e.g. anemometers, to measure velocity at different elevations and locations that are more costly sensors compared to the temperature measurements. In addition, a literature review indicates that the simulated temperature values are more dependent on the thermal heat flux approximations, especially close to the impervious surfaces, rather than the simulated velocities [26]. Due to the cost of anemometers and the specific requirements for the installation of the anemometers in limited access locations, e.g. roofs, consideration of multiple anemometers for the desired locations is impractical. These requirements suggest benefiting from a framework that is cost effective and empower installation of sensors for the desired locations. For example, this case study is an administrative building that thousands of people pass through the sidewalks. Even with permission of the university facilities, emergency signs, and careful supervision of the instruments, three temperature sensors and a measurement pool were lost. If the sensors were anemometers, the cost of losing sensors would have been an order of magnitude higher than the current cost of losing. Consequently, this study benefited from the indirect validation of the temperature measurements, suggesting when the simulated temperature results are successfully validated, one could conclude that the wind velocities are most likely in agreement with the actual values. Therefore, this study executed the temperature validation, rather than the velocity validation to costeffectively meet a more stringent requirement for the validation.

\section{Conclusions}

This paper develops a framework to create wind multipliers using Computational Fluid Dynamics (CFD) for calibration of building energy models for buildings located in urban neighborhoods. This study validates the results and provides recommendations for future studies to deploy the developed wind multipliers in urban neighborhoods with different urban plan area densities. The validation efforts in this study include (1) validation of the CFD simulation results with the on-site measured temperatures, and (2) calibration of the building energy model with the actual building utility data for a selected case study located at the University of Maryland campus. The CFD validation results indicate that the simulated temperature results for the selected case study are within the accuracy of the deployed sensors. In addition, y-plus, a measure of the deployed mesh quality, is within the acceptable range $\left(\mathrm{y}^{+} \leq 300\right)$. Furthermore, even though the baseline energy model meets the operational schedules of the building, it does not accurately reflect the actual utility data, suggesting the need to incorporate the influence of urban neighborhood into the building energy modeling.

To calibrate the building energy model, this study performs CFD simulations for eight principal wind directions to develop wind multipliers. These wind multipliers provided the adjusted weather data files for the building energy modeling. The building energy models based on the adjusted weather files have CVRSME of $9 \%$ and NMBE $0 \%$ for electricity consumption, and CVRSME of $14 \%$ and NMBE $1 \%$ for steam consumption in heating season. The results of this study support the calibration of building energy models for buildings located in an urban neighborhood. The results of implementing adjusted weather data in the building energy modeling show that the load patterns of the building vary significantly. The impact is more significant on the peak sensible cooling heat gains compared to the sensible heating heat gains. For example, the adjusted weather data led to $31 \%$ and $29 \%$ reductions in infiltration heat gain and heat loss for peak cooling and heating sensible heat gain components, respectively. The integrated changes in both heating and cooling demands result in 5\% decrease in the total energy demand for the studied building located in a Northeastern USA. Overall, this study confirms and quantifies the impact of urban neighborhoods on the energy consumption patterns of buildings.

\section{Acknowledgements}

This study is sponsored by the EFRI-1038264/1452045 awards from the National Science Foundation (NSF), Division of Emerging Frontiers in Research and Innovation (EFRI). Authors would like to thank Calvin Chi for helping in the data collection. Authors also would like to thank Ling Chen and Richard Mistrick for providing the 
solar radiation simulation results for the validation study. Authors acknowledge continuous support of Stefan Gracik with the CFD simulations that represent a continuation of his M.Sc. thesis work.

\section{References}

[1] J. Srebric, M. Heidarinejad, J. Liu, Building neighborhood emerging properties and their impacts on multi-scale modeling of building energy and airflows, Build Environ, 91 (0) (2015) 246-262.

[2] Y. Toparlar, B. Blocken, P. Vos, G.J.F. van Heijst, W.D. Janssen, T. van Hooff, H. Montazeri, H.J.P. Timmermans, CFD simulation and validation of urban microclimate: A case study for Bergpolder Zuid, Rotterdam, Build Environ, 83 (0) (2015) 79-90.

[3] X. Yang, L. Zhao, M. Bruse, Q. Meng, An integrated simulation method for building energy performance assessment in urban environments, Energ Buildings, 54 (0) (2012) 243-251.

[4] N. Yaghoobian, J. Kleissl, An indoor-outdoor building energy simulator to study urban modification effects on building energy use - Model description and validation, Energ Buildings, 54 (0) (2012) 407-417.

[5] B. Bueno, L. Norford, G. Pigeon, R. Britter, Combining a Detailed Building Energy Model with a PhysicallyBased Urban Canopy Model, Boundary-Layer Meteorology, 140 (3) (2011) 471-489.

[6] T. Ayata, Investigation of building height and roof effect on the air velocity and pressure distribution around the detached houses in Turkey, Appl Therm Eng, 29 (8-9) (2009) 1752-1758.

[7] X. Meng, Y. Wang, T. Liu, X. Xing, Y. Cao, J. Zhao, Influence of radiation on predictive accuracy in numerical simulations of the thermal environment in industrial buildings with buoyancy-driven natural ventilation, Appl Therm Eng, 96 (2016) 473-480.

[8] C.A. Conceição António, J.B. Monteiro, C.F. Afonso, Optimal topology of urban buildings for maximization of annual solar irradiation availability using a genetic algorithm, Appl Therm Eng, 73 (1) (2014) 424-437.

[9] M. Heidarinejad, S. Gracik, M. Sadeghipour Roudsari, S. Khoshdel Nikkho, J. Liu, K. Liu, G. Pitchorov, J. Srebric, Influence of building surface solar irradiance on environmental temperatures in urban neighborhoods, Sustainable Cities and Society, 26 (2016) 186-202.

[10] L. Zhang, N. Zhang, F. Zhao, Y. Chen, A genetic-algorithm-based experimental technique for determining heat transfer coefficient of exterior wall surface, Appl Therm Eng, 24 (2-3) (2004) 339-349.

[11] J.A. Palyvos, A survey of wind convection coefficient correlations for building envelope energy systems' modeling, Appl Therm Eng, 28 (8-9) (2008) 801-808.

[12] P. Karava, C.M. Jubayer, E. Savory, Numerical modelling of forced convective heat transfer from the inclined windward roof of an isolated low-rise building with application to photovoltaic/thermal systems, Appl Therm Eng, 31 (11-12) (2011) 1950-1963.

[13] J. Liu, M. Heidarinejad, M. Guo, J. Srebric, Numerical Evaluation of the Local Weather Data Impacts on Cooling Energy Use of Buildings in an Urban Area, Procedia Engineering, 121 (2015) 381-388.

[14] J. Wei, J. He, Numerical simulation for analyzing the thermal improving effect of evaporative cooling urban surfaces on the urban built environment, Appl Therm Eng, 51 (1-2) (2013) 144-154.

[15] P.C. Tabares-Velasco, M. Zhao, N. Peterson, J. Srebric, R. Berghage, Validation of predictive heat and mass transfer green roof model with extensive green roof field data, Ecol Eng, 47 (0) (2012) 165-173.

[16] S. Obyn, G. van Moeseke, Variability and impact of internal surfaces convective heat transfer coefficients in the thermal evaluation of office buildings, Appl Therm Eng, 87 (2015) 258-272.

[17] J. Liu, J. Srebric, N. Yu, Numerical simulation of convective heat transfer coefficients at the external surfaces of building arrays immersed in a turbulent boundary layer, Int J Heat Mass Tran, 61 (0) (2013) 209-225.

[18] J. Liu, M. Heidarinejad, S. Gracik, J. Srebric, The impact of exterior surface convective heat transfer coefficients on the building energy consumption in urban neighborhoods with different plan area densities, Energ Buildings, 86 (0) (2015) 449-463.

[19] M. Mirsadeghi, D. Cóstola, B. Blocken, J.L.M. Hensen, Review of external convective heat transfer coefficient models in building energy simulation programs: Implementation and uncertainty, Appl Therm Eng, 56 (1-2) (2013) 134-151.

[20] J. Liu, M. Heidarinejad, S. Gracik, J. Srebric, N. Yu, An indirect validation of convective heat transfer coefficients (CHTCs) for external building surfaces in an actual urban environment, Build. Simul., 8 (3) (2015) 337352.

[21] T. van Hooff, B. Blocken, J.L.M. Hensen, H.J.P. Timmermans, On the predicted effectiveness of climate adaptation measures for residential buildings, Build Environ, 82 (2014) 300-316.

[22] M.W. Liddament, M. Orme, Energy and ventilation, Appl Therm Eng, 18 (11) (1998) 1101-1109.

[23] M.H. Sherman, Air infiltration in buildings, 1980. 
[24] S.J. Emmerich, A.K. Persily, Energy impacts of infiltration and ventilation in US office buildings using multizone airflow simlation, Proceedings of IAQ and Energy, 1998.

[25] S. Gracik, M. Heidarinejad, J. Liu, J. Srebric, Effect of urban neighborhoods on the performance of building cooling systems, Build Environ, 90 (0) (2015) 15-29.

[26] M. Heidarinejad, N.W. Mattise, M. Dahlhausen, K. Sharma, K. Benne, D. Macumber, J. Srebric, Modeling of impacts of urban neighborhood on building energy consumption, ASHRAE/IBPSA 2016 (Abstract Submitted), 2016.

[27] J. Franke, A. Hellsten, H. Schlünzen, B. Carissimo. Best practice guideline for the CFD simulation of flows in the urban environment. COST; 2007.

[28] M. Heidarinejad, N. Mattise, M. Dahlhausen, S. Khoshdel Nikkho, J. Liu, S. Gracik, K. Liu, K. Sharma, H. Zhang, J.R. Wentz, M. Sadeghipour Roudsari, G. Pitchurov, J. Srebric, Urban scale modeling of campus building using Virtual PULSE, Building Simulation 2015, 2015.

[29] EnergyPlus Engineering Reference, 2014.

[30] L.C. Ng, A.K. Persily, S.J. Emmerich, Improving infiltration modeling in commercial building energy models, Energ Buildings, 88 (0) (2015) 316-323.

[31] P.J. Roache. Verfication and validation in computational science and engineering. New Mexico1998.

[32] P.J. Roache, Perspective: A Method for Uniform Reporting of Grid Refinement Studies, Journal of Fluids Engineering, 116 (3) (1994) 405-413.

[33] ASHRAE Guideline 14-2002: Measurement of Energy and Demand Savings, ASHRAE, 2002.

[34] M. Heidarinejad, Relative significance of heat transfer processes to quantify tradeoffs between complexity and accuracy of energy simulations with a building energy use patterns classification, Mechanical Engineering, Pennsylvania State University, 2014.

[35] E. Hale, L. Lisell, D. Goldwasser, D. Macumber, J. Dean, I. Metzger, A. Parker, N. Long, B. Ball, M. Schott, E. Weaver, L. Brackney, Cloud-Based Model Calibration Using OpenStudio, eSim 2014, Ottawa, Canada, 2014.

[36] R.a.A.-C.E. American Society of Heating, Inc. (ASHRAE), ASHRAE Standard 62.1, "Ventialtion for Acceptable Indoor Air Quality, Atlanta, GA, 2013.

[37] G. Han, J. Srebric, E. Enache-Pommer, Different modeling strategies of infiltration rates for an office building to improve accuracy of building energy simulations, Energ Buildings, 86 (0) (2015) 288-295.

[38] D.M. Hargreaves, N.G. Wright, On the use of the k- model in commercial CFD software to model the neutral atmospheric boundary layer, Journal of Wind Engineering and Industrial Aerodynamics, 95 (5) (2007) 355-369.

[39] K. Niachou, I. Livada, M. Santamouris, Experimental study of temperature and airflow distribution inside an urban street canyon during hot summer weather conditions-Part I: Air and surface temperatures, Build Environ, 43 (8) (2008) 1383-1392.

[40] J.W. Slater. Overview of CFD Validation and Verification. NASA; 1998.https://www.grc.nasa.gov/WWW/wind/valid/tutorial/overview.html.

[41] M. Hajdukiewicz, M. Geron, M.M. Keane, Formal calibration methodology for CFD models of naturally ventilated indoor environments, Build Environ, 59 (2013) 290-302.

[42] F. Systems. FLIR Systems: FLIR E series datasheet. 2013.http://www.flir.com.

[43] J. Allegrini, V. Dorer, J. Carmeliet, Coupled CFD, radiation and building energy model for studying heat fluxes in an urban environment with generic building configurations, Sustainable Cities and Society.

[44] D. Botham-Myint, G.W. Recktenwald, D.J. Sailor, Thermal footprint effect of rooftop urban cooling strategies, Urban Climate.

[45] N. Nazarian, J. Kleissl, CFD simulation of an idealized urban environment: Thermal effects of geometrical characteristics and surface materials, Urban Climate, 12 (0) (2015) 141-159.

[46] P.A. Mirzaei, J. Carmeliet, Dynamical computational fluid dynamics modeling of the stochastic wind for application of urban studies, Build Environ, 70 (2013) 161-170.

[47] T. van Hooff, B. Blocken, Coupled urban wind flow and indoor natural ventilation modelling on a highresolution grid: A case study for the Amsterdam ArenA stadium, Environmental Modelling \& Software, 25 (1) (2010) 51-65.

[48] J. Liu, M. Heidarinejad, S. Gracik, D. Jareemit, J. Srebric, The Impact of Surface Convective Heat Transfer Coefficients on the Simulated Building Energy Consumption and Surface Temperatures, Indoor Air, Hong Kong, 2014. 